\title{
Incidence and prevalence of falls in adults with an intellectual disability living in the community: a systematic review
}

Portia Ho, ${ }^{1,2}$ Max Bulsara, ${ }^{3}$ Jenny Downs, ${ }^{4,5}$ Shane Patman, ${ }^{1}$ Caroline Bulsara, ${ }^{3}$ Anne-Marie Hill ${ }^{5}$

1 School of Physiotherapy, the University of Notre Dame Australia, Fremantle, Australia, ${ }^{2}$ The

Western Australian Group for Evidence Informed Healthcare Practice: a Joanna Briggs Institute

Centre of Excellence, ${ }^{3}$ Institute for Health Research, the University of Notre Dame Australia,

Fremantle, Australia, ${ }^{4}$ Telethon Kids Institute, Subiaco, Western Australia, Australia, and ${ }^{5}$ School of

Physiotherapy and Exercise Science, Curtin University, Perth, Australia

\section{ABSTRACT}

\section{Background}

Falls among adults with intellectual disability (ID) frequently cause physical injury and may negatively impact on quality of life. Studies investigating falls among people with ID have used differing methods and populations, making it difficult to determine the scope and extent of this problem.

\section{Objective}

To synthesize the best available evidence to determine the incidence and prevalence of falls among adults with ID.

Inclusion criteria

Types of participants

This review considered all studies that included adults with ID aged 18 years and older.

\section{Condition}

The current review considered studies which reported percentage/numbers of individuals who fell, and the total number of falls and injurious falls sustained from a fall.

\section{Context}

Studies were included if they were conducted within community or residential settings. Studies that were conducted in hospitals were excluded.

\section{Types of studies}

Cohort studies, case-control and cross-sectional studies were included. Studies that used an experimental design, both randomized controlled and quasi experimental design were also included.

\section{Search Strategy Methods}

A three-step search strategy was undertaken for published and unpublished literature in English from 1990 to 2017. An initial search of MEDLINE and CINAHL was undertaken before 
a more extensive search was conducted using keywords and index terms across 11 electronic databases.

\section{Methodological Quality}

Two independent reviewers assessed the methodological quality of the included studies using Joanna Briggs Institute standardized critical appraisal instrument for prevalence studies (Joanna Briggs Institute Critical Appraisal Checklist for Studies Reporting Prevalence Data).

\section{Data extraction}

Data was extracted using the standardized extraction tool from the Joanna Briggs Institute's System of the Unified Management, Assessment and Review Information. Data that directly reported or could be used to calculate the incidence and prevalence of falls were extracted.

\section{Data synthesis}

Quantitative data for the number (proportion) of people who fell were pooled in statistical meta-analysis using STATA version 14. Data measuring incidence of falls (rate of falls for the duration of the study) and incidence of injurious falls (rate of falls resulting in one or more injuries for the duration of the study) could not be pooled in meta-analysis, hence results were presented in a narrative form including tables. Standard GRADE (Grading of Recommendations Assessment, Development and Evaluation) evidence assessment of outcomes is also reported.

\section{Results}

Nine studies were eligible for inclusion in this review. Eight articles were observational cohort studies which reported on the incidence/prevalence of falls as outcome measures, one article was a quasi-experimental study design. Overall the methodological quality of the included studies was considered moderate. The pooled proportion of people with ID who fell (4 studies, 854 participants) was $39 \%$ [ $95 \% \mathrm{Cl}(0.35 \%-0.43 \%)$, very low GRADE evidence]. The rate of falls ( 8 studies, 782 participants) ranged from 0.54 to 6.29 per person year (very low GRADE evidence). The rate of injurious falls ( 2 studies, 352 participants) ranged from 0.33 to 0.68 per person year (very low GRADE evidence).

\section{Conclusions}

Synthesized findings demonstrate that people with ID, who live in community or residential settings, may fall more frequently, and at a younger age, compared to general community populations. Studies should take a consistent approach to measuring and reporting falls outcomes. Further research is recommended to identify the impact of falls on health related outcomes for people with ID and subsequently evaluate falls interventions for their efficacy.

\section{Keywords}


Falls, injurious falls, intellectual disability, developmental disability, community 


\section{Summary of Findings}

\begin{tabular}{|c|c|c|c|c|c|c|c|c|c|}
\hline \multicolumn{7}{|c|}{ Certainty Assessment } & \multirow[b]{2}{*}{ Results } & \multirow[b]{2}{*}{ Certainty } & \multirow[b]{2}{*}{ Importance } \\
\hline $\begin{array}{c}\text { № of } \\
\text { studies }\end{array}$ & Study design & $\begin{array}{c}\text { Risk of } \\
\text { bias }\end{array}$ & Inconsistency & Indirectness & Imprecision & Other Considerations & & & \\
\hline \multicolumn{10}{|c|}{ Proportion of people who experienced one or more falls (follow up: 12 months; assessed with: retrospective recall, prospective incident reporting, daily recording) } \\
\hline 4 & $\begin{array}{l}\text { observational } \\
\text { studies }\end{array}$ & serious a & not serious & not serious & serious ${ }^{b}$ & $\begin{array}{l}\text { publication bias strongly } \\
\text { suspected } \\
\text { strong association c }\end{array}$ & $\begin{array}{l}39 \text { per } 100 \text { participants fell }(95 \% \\
\mathrm{Cl} 35 \text { to } 43)\end{array}$ & $\begin{array}{l}\oplus \bigcirc \bigcirc \bigcirc \\
\text { VERY } \\
\text { LOW }\end{array}$ & CRITICAL \\
\hline \multicolumn{10}{|c|}{ Incidence of falls (follow up: range 3 months to 33 months; assessed with: daily recording of falls, prospective incident reporting) } \\
\hline 8 & $\begin{array}{l}\text { observational } \\
\text { studies }\end{array}$ & serious $^{d}$ & very serious ${ }^{e}$ & not serious & very serious ${ }^{\mathrm{e}}$ & $\begin{array}{l}\text { publication bias strongly } \\
\text { suspected } \\
\text { strong association c }\end{array}$ & $\begin{array}{l}\text { Falls rate range from } 0.54 \text { to } \\
6.29 \text { falls per person year }\end{array}$ & $\begin{array}{c}\oplus \bigcirc \bigcirc \bigcirc \\
\text { VERY } \\
\text { LOW }\end{array}$ & CRITICAL \\
\hline \multicolumn{10}{|c|}{ Incidence of falls that resulted in one or more injuries (follow up: range 12 months to 33 months; assessed with: Prospective incident reporting) } \\
\hline 2 & $\begin{array}{l}\text { observational } \\
\text { studies }\end{array}$ & serious $^{f}$ & not serious & not serious & serious $g$ & $\begin{array}{l}\text { publication bias strongly } \\
\text { suspected c }\end{array}$ & $\begin{array}{l}\text { Injurious falls rates range from } \\
0.33 \text { to } 0.68 \text { per person year }\end{array}$ & $\begin{array}{l}\oplus \bigcirc \bigcirc \bigcirc \\
\text { VERY } \\
\text { LOW }\end{array}$ & CRITICAL \\
\hline
\end{tabular}

\section{Cl: Confidence interval}

\section{GRADE Working Group grades of evidence}

High certainty: We are very confident that the true effect lies close to that of the estimate of the effect.

Moderate certainty: We are moderately confident in the effect estimate: The true effect is likely to be close to the estimate of the effect, but there is a possibility that it is substantially different.

Low certainty: Our confidence in the effect estimate is limited: The true effect may be substantially different from the estimate of the effect.

Very low certainty: We have very little confidence in the effect estimate: The true effect is likely to be substantially different from the estimate of effect.

\section{Explanations}

a. Falls events not measured according to recommended guidelines in three of four studies $4,6,15$

b. Imprecision: The confidence intervals across the four studies $4,6,14,16$ ranges from $26 \%$ to $57 \%$, indicating a degree of uncertainty of the weighted effect size (39\%). 
c. Publication bias is suspected to be serious as authors found published conference abstracts regarding the prevalence of falls in people with ID, but these studies were not found in the systematic search to be included in this review.

d. Only one study ${ }^{14}$ collected falls data according to recommended guidelines and the severity of participants' intellectual disability or participants' co-morbidities are not always specified.

e. The estimated falls rates vary widely (and show inconsistent variance when compared to the fall rates of community dwelling older people (known to be approximately 1.2 falls per person year). ${ }^{33}$

f. Only two studies were able to be included in the analysis.., 16

g. The injurious falls rates vary in the two studies. 5,16 


\section{BACKGROUND}

In 2014, between 100,000 to 120,000 Australians over the age of 65 were admitted to hospital after sustaining a fall related injury, with each admission being on average eight days. ${ }^{1}$ The estimated direct health care cost for falls was over AUD $\$ 498$ million in 2001 and this is projected to increase to AUD $\$ 1.4$ billion in 50 years' time. ${ }^{2}$

People with ID are particularly vulnerable to falling. ${ }^{3-5} \mathrm{~A}$ diagnosis of ID is made when an individual had either an IQ score lower than 75 or limited intellectual and adaptive functioning, ${ }^{4-8}$ as per the criteria defined in the American Psychological Society ${ }^{9} 5^{\text {th }}$ edition of the Diagnostic and Statistical Manual of Mental Disorders (DSM-5). People with ID share similar risk factors for falls to those of older people such as reduced muscle strength and balance, ${ }^{1}$ but they also have additional risk factors such as epilepsy ${ }^{10}$ and reduced safety. ${ }^{11}$ Falls may be a problem for people with ID at a younger age compared to older community dwelling adults, as many experience age-related changes from their third decade of life. ${ }^{12,13}$

It is challenging to establish the rate of falls in adults with ID due to high heterogeneity in both study methods and reported data. ${ }^{4-8,14-16}$ Studies conducted in adults with ID suggest that the rate of falls varies widely and may be up to 6.29 falls per person year. ${ }^{8}$ Falls research guidelines recommend that falls data should be collected prospectively with daily recording of falls and a minimum of monthly follow-ups by the research team. ${ }^{17}$ These recommended guidelines for falls research can be difficult to implement among people with ID due to challenges implementing informed consent processes ${ }^{18}$ and difficulties in engaging people with ID in research. ${ }^{19}$ Falls and falls injuries are recommended to be reported as rates, and reporting the proportion of participants who fall within the observational period is also recommended, ${ }^{17}$ however previous studies have not always reported these outcome

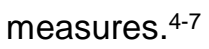

A variety of methods for collecting and measuring falls data have been used. Some studies collected falls data prospectively, whilst others used retrospective data collection. For the studies that collected data prospectively, only one study collected daily recordings of falls. ${ }^{14}$ Other studies relied on organizational incident reports or recording the number of falls based on participants' reports at the end of the study period. ${ }^{4-8}$ This method of data collection is not recommended as recall data has been found affect accuracy in the area of falls research. 17,20 The studies also encompassed varied settings and participant groups. ${ }^{4-8,14}$ Participants' ages ranged from 16 to 89 years old. 6,16 Participants were also recruited participants with a variety of living arrangements including, residential facilities, campus facilities, living independently or living in shared housing with formal care arrangements. 4-8,14-16 Therefore, it is challenging to determine the incidence of falls in specific populations of people with ID. It is important to make this distinction and also to establish the incidence and prevalence of falls among adults with ID to be able to quantify the extent of the problem, and to subsequently allow robust testing of falls reduction interventions and development of services that are specifically suitable for these populations.

Large systematic reviews have examined the prevalence and incidence of falls among older people living in the community ${ }^{1,21}$ but no review has specifically synthesized the evidence for the prevalence 
and incidence of falls among adults with ID. Previous reviews of falls among people with ID have primarily focused on risk factors and preventative strategies, ${ }^{10}$ gait and balance capacities ${ }^{22}$ and prevention of unintentional injury. ${ }^{23}$ No review has specifically synthesized the evidence for the prevalence and incidence of falls among adults with ID to identify the underlying scope of the problem.

An initial search of The Cochrane Database of Systematic Reviews, The JBI Database of Systematic Reviews and Implementation Reports (JBISRIR), PubMed, CINAHL and PROSPERO found no systematic reviews underway on this topic. It is therefore necessary to synthesize the findings of the studies that have been conducted on this area to appraise the strengths and limitations of such studies and to identify the evidence about the prevalence and incidence of falls among adults with ID. The negative impacts and high economic burden of falls among older people ${ }^{24}$ are well established and a precise estimate of falls prevalence and incidence in adults with ID will allow a direct comparison with the incidence of falls in the broader community dwelling population. The objective and methods for conducting this review were specified in advance in a JBI systematic review protocol. ${ }^{25}$

\section{OBJECTIVE}

The objective of this review was to synthesize the best available evidence in order to determine the incidence and prevalence of falls among adults with ID living in the community.

\section{INCLUSION CRITERIA}

\section{Types of participants}

This review considered studies, conducted worldwide, that included people with mild to severe levels of ID according to the severity classification in the DSM-5. ${ }^{9}$ Studies that used the term 'learning disability' which uses the same criteria as ID in DSM-5 were also included. Studies that used a broader inclusion criteria of 'developmental disability' 26 were also included as these studies would likely have included participants with ID, since ID is one type of developmental disability The review considered studies involving participants aged 18 years and older. Studies that included participants younger than 18 years were included if the mean age was 18 years or older, or if data from participants who were 18 years or older could be separately extracted.

Studies that included only participants who were under 18 years of age, adults who had a cognitive impairment resulting from an acquired brain injury or age-related diseases of cognition, such as dementia, were excluded.

\section{Condition}

The World Health Organization has defined a fall as 'an event which results in a person coming to rest inadvertently on the ground or floor or other lower level'27(p.1) and a fall was classified as injurious if it resulted in bruising, laceration, dislocation, fracture or complaining of the onset of persistent pain as a result of the fall. ${ }^{28}$ Studies were included in this review if they reported on falls prevalence and/or 
incidence as a primary or secondary outcome measure. Outcome measures could include the rate of falls (expressed as the number of falls experienced by participants during the total observation period of the study, i.e. falls per person year, number of falls per 1000 person days), the proportion of participants who became fallers (expressed percentage of participants who fell), the rates of injurious falls (expressed as the number of falls with injury experienced by participants during the observation period i.e. injurious falls per person year, number of falls with injury per 1000 person days), and the proportion of participants who had an injurious fall (expressed as the number of participants who sustained an injury as a result of a fall). Studies which did not provide the above data but provided data which could be used to calculate the falls or injurious falls rate per person time or the proportion/number of participants who fell one or more times were also included.

\section{Context}

This review considered all studies which included participants with ID who lived in either community based settings or residential facilities. This context differs from the stated protocol ${ }^{25}$ for this systematic review, which stipulated that only participants with ID living in community based settings would be considered. Some studies reviewed during the present search included participants who lived in a variety of community settings, but did not describe the exact nature of the setting, making it challenging to distinguish if these participants were living in a residential facility, community or an accommodation setting that had both types of living arrangements. Studies which were conducted in hospitals or studies that included participants who were in a hospital setting remained excluded.

\section{Types of studies}

This review considered studies with an observational design, including prospective and retrospective cohort studies, case-control and cross sectional studies. Due to the paucity of literature in this area, studies that used an experimental design, both randomized controlled and quasi-experimental designs were included. Single-case studies were excluded.

\section{METHODS}

This review was undertaken in accordance with the protocol published in the JBI Database of Systematic Reviews and Implementation Reports entitled 'Incidence and prevalence of falls in adults with ID living in the community: a systematic review protocol'25 and used the recommended JBI guidelines for conducting a systematic review of prevalence and incidence data. ${ }^{29}$

\section{Search strategy}

A three-step search strategy was used to identify both published and unpublished studies written in English. First a limited search of MEDLINE and CINAHL was undertaken using an initial set of key words (fall, falls prevention, intellectual disability), followed by the analysis of the text words contained in the title, abstract and the index terms used to describe the article. Second, an extended search using all identified keywords and index terms was undertaken across 11 databases. Search strategies for all databases are displayed in Appendix I. Third, the reference lists of all identified reports and 
articles retrieved for their full-text were searched for additional studies.

MEDLINE, CINAHL, Embase and PsycINFO were databases searched via the EbscoHost platform and the AMED database was searched via the Ovid platform. The Cochrane Central Register of Controlled Trials (CENTRAL) was also searched. A clinical trial registry database, Current Controlled Trials (http://www.isrctn.com) and the National Institute of Health Clinical Database (http://www.cliniclaltrials.gov) were also searched. The search for unpublished studies was conducted using TROVE, Google Scholar and ProQuest Theses and Dissertations. For specific research into people with ID the websites of Rehabilitation Research and Training Center on Developmental Disabilities and Health (rrtcadd.org), Centre for Developmental Disability Health Victoria (www.cddh.monash.org) and the Centre for Applied Disability Research (www.cadr.org.au) were also searched. All retrieved results were individually examined for potential inclusion in the review.

\section{Study Selection}

Studies published from 1990 to December 2017 were considered for inclusion. The start date of 1990 was considered appropriate as research into falls prevention is a relatively recent field of research and other large systematic reviews investigating the evidence for falls interventions ${ }^{30,31}$ have included studies dating from 1990. ${ }^{32,33}$ All studies identified were retrieved and examined by two independent reviewers $(\mathrm{PH}, \mathrm{JD})$ who read the title and abstract, to ensure relevance and that they met the inclusion criteria with arbitration about final inclusion from a third independent reviewer (AMH) if required.

\section{Assessment of methodological quality}

Articles selected for retrieval were assessed by two independent expert reviewers (SP, JD) for methodological validity before they were included in the review using the Joanna Briggs Institute standardized critical appraisal instrument for prevalence studies (Joanna Briggs Institute Critical Appraisal Checklist for Studies Reporting Prevalence Data). ${ }^{29}$ The checklist for prevalence studies were also used for experimental studies with the checklist being used to appraise how the baseline falls data were collected and analyzed, as that was the outcome of interest for this review. Any disagreements that arose between the reviewers were resolved through discussions, or by further discussion with a third reviewer $(\mathrm{AMH})$. Guidelines for conducting falls research ${ }^{17,20}$ recommend that prospective falls data collection is undertaken to reduce recall bias, therefore question seven of the critical appraisal (Was the condition measured in a reliable way?) was rated "No" if falls data were collected based on recall. Studies that scored five or more 'Yes' ratings out of nine were included in the review.

\section{Data Extraction}

Quantitative data were extracted from the selected studies by the two independent reviewers $\mathrm{PH}$, $\mathrm{AMH}$ ) using the standardized extraction tool from the Joanna Briggs Institute's System of the Unified Management, Assessment and Review Information (JBI SUMARI), version 5, 2016. ${ }^{34}$ Data that included specific details about the populations, study methodology and outcomes of significance or 
those that allowed the outcomes of significance to be calculated (number of falls, falls rates, number/proportion of people who fell, number of injurious falls and injurious falls rates) were extracted. For the one study ${ }^{35}$ that used an experimental design, data extracted included the falls data that were collected at baseline only. Any disagreements that arose between the reviewers were resolved through discussions, and where necessary a third reviewer (SP) was asked to make a final decision.

\section{Data Synthesis}

All data were subjected to double data entry. Statistical meta-analysis was conducted for the outcome of number of fallers (proportion of people who fell). The number of fallers and non-fallers in each group were entered and data were pooled using STATA version 14 (StataCorp, College Station, TX, USA), using the metaprop command. Metaprop implements procedures which are specific to binomial data. ${ }^{36}$ It computes $95 \%$ confidence intervals using the score statistic and the exact binomial method and incorporates the Freeman-Tukey double arcsine transformation of proportions. ${ }^{37}$ This also allows the within-study variability to be modelled using the binomial distribution. A random effects model was used to calculate estimates. Heterogeneity was assessed using the $\mathrm{I}^{2}$ squared statistic and was rated as low, moderate or high. ${ }^{38}$ Heterogeneity was subsequently explored by undertaking a sensitivity analysis, based on the methods that the studies used to collect falls data, including whether falls data were collected using prospective or retrospective data collection methods.

The number of falls in each study and the days of observation were used to calculate the incidence as a rate per person year. It was not possible to pool the incidence rates for the included studies because patient level data were not presented and neither were data which would allow an estimate of the degree of uncertainty of the incidence rate reported, such as the standard error of the falls rate data. Therefore results for falls rates were presented as falls per person year for each study and summarized in table form. The studies that reported the number of injurious falls or the number of people who sustained an injurious fall also did not report patient level data or data that would allow an estimate of the degree of uncertainty, therefore these data were not pooled for meta-analysis and were presented as a narrative synthesis with a table of results.

\section{RESULTS}

\section{Study inclusion}

After all databases were searched and duplicates were removed from retrieved records, 2951 titles and/or abstracts were screened (Appendix I). Articles that did not fit the inclusion criteria were excluded resulting in 22 citations identified as appropriate for detailed assessment. 13 studies were excluded after reading the full text. These studies were excluded because the outcomes of interest (prevalence/incidence of falls) were either not measured in these studies or could not be calculated from the data collected in the study. Where the same cohort of participants were used in multiple studies their data were only included once. Studies that were conducted in a population that did not meet inclusion criteria, such as participants being under 18 years old, were excluded. The excluded 
studies and their reasons for exclusion are presented in Appendix II. The remaining nine articles were selected for critical appraisal and all were included in the analysis. The study selection and inclusion process is detailed in the PRISMA ${ }^{39}$ flowchart (Figure 1).

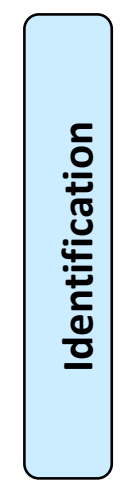

Number of records identified through a systematic search (MEDLINE $=287$, CINAHL $=67$, PsycINFO $=221$, Cochrane CENTRAL $=27$, AMED $=$ 58, Embase $=302$ ISRCTN reg $=37$, ClinicalTrials $=7)(\mathrm{N}=1006)$
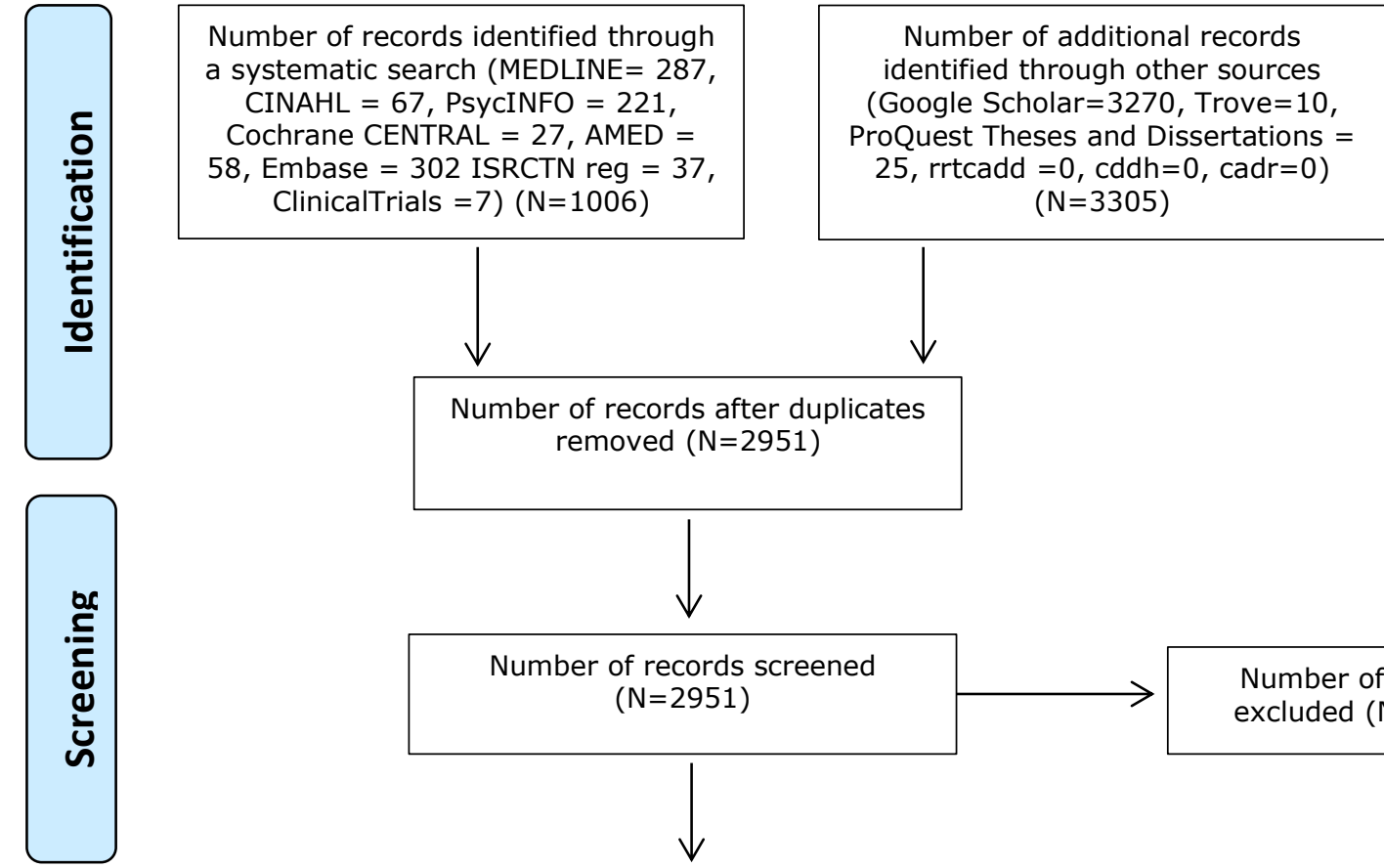

Number of records after duplicates removed $(\mathrm{N}=2951)$

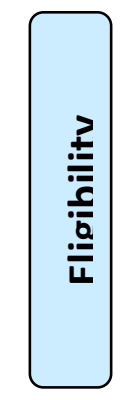

Number of full-text articles assessed for eligibility $(\mathrm{N}=22)$
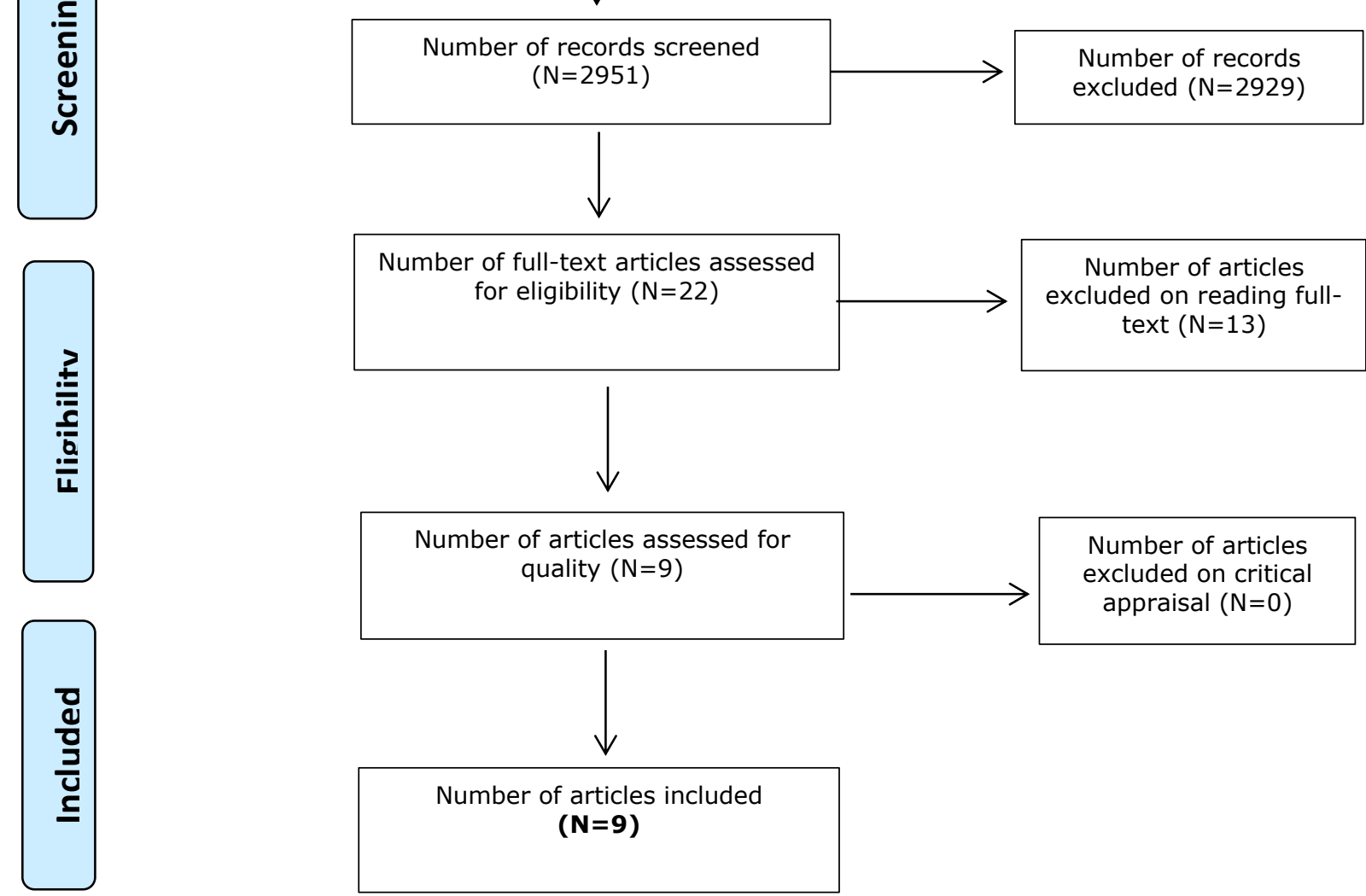

Number of articles assessed for quality $(\mathrm{N}=9)$

Number of articles excluded on critical appraisal $(\mathrm{N}=0)$

From: Moher D, Liberati A, Tetzlaff J, Altman DG, The PRISMA Group (2009). Preferred Reporting Items for Systematic Reviews and Mata-Analyses: The PRISMA Statement. PLoS Med 6(7):e1000097.

\section{Figure 1: PRISMA flow diagram of search and study selection process}




\section{Methodological quality}

The nine included studies were critically appraised by the two independent reviewers (SP, JD) using the Joanna Briggs Institute's standardized critical appraisal instrument for prevalence studies (Joanna Briggs Institute Critical Appraisal Checklist for Studies Reporting Prevalence Data). ${ }^{29}$ The checklist for prevalence studies was also used for the single quasi-experimental study, where the appraisal was focused on how the baseline falls data were collected and analyzed. The eight studies that investigated the incidence or prevalence of falls in people with ID scored between six to eight out of nine, and were considered of an acceptable quality for inclusion in meta-analysis. One study (Van Hanegem et al, 2014) ${ }^{34}$ scored five out of nine: this was a quasi-experimental study and falls data collected at baseline were examined. This study scored well on the selection of the sample but not on the measurement and analysis of the falls data. Five of the nine studies reported that they used a recommended method of collecting falls data, namely, prospective data collection with regular follow ups (Table 1, Q7). Four of the nine studies scored 'No' on selecting an appropriate sample as one study ${ }^{14}$ excluded people with ID who had a diagnoses of Epilepsy, two studies ${ }^{16,5}$ had a significantly higher proportion of women and one had a small sample size ${ }^{35}$. One study ${ }^{8}$ did not describe participants' level of ID and this study was rated as 'Unsure'. Results of the methodological quality evaluation are shown in Table 1. 
Table 1 Methodological assessment scores of the included studies using Joanna Briggs Institute's standardized critical appraisal instrument for prevalence studies

\begin{tabular}{|c|c|c|c|c|c|c|c|c|c|c|}
\hline Citation & Q1 & Q2 & Q3 & Q4 & Q5 & Q6 & Q7 & Q8 & Q9 & Total score \\
\hline Cox et al, $2010^{4}$ & $\mathrm{Y}$ & $\mathrm{Y}$ & $\mathrm{Y}$ & $\mathrm{Y}$ & $\mathrm{Y}$ & $U$ & $\mathrm{~N}$ & $\mathrm{Y}$ & $\mathrm{Y}$ & 7 \\
\hline $\begin{array}{l}\text { Finlayson et al, } \\
2010^{6}\end{array}$ & $\mathrm{Y}$ & $\mathrm{Y}$ & $\mathrm{Y}$ & $\bar{Y}$ & $\bar{Y}$ & $\mathrm{~N}$ & $\mathrm{~N}$ & $\bar{Y}$ & $\mathrm{Y}$ & 7 \\
\hline $\begin{array}{l}\text { Grant et al, } \\
2001^{15}\end{array}$ & $\mathrm{Y}$ & $\mathrm{N}$ & $\mathrm{Y}$ & $\mathrm{Y}$ & $\bar{Y}$ & $\bar{Y}$ & $\bar{Y}$ & $\mathrm{~N}$ & $\mathrm{Y}$ & 7 \\
\hline $\begin{array}{l}\text { Hsieh et al, } \\
2012^{7}\end{array}$ & $\mathrm{Y}$ & $\mathrm{N}$ & $\mathrm{Y}$ & $Y$ & $\mathrm{Y}$ & $\mathrm{N}$ & $\mathrm{N}$ & $\mathrm{Y}$ & $Y$ & 6 \\
\hline Pal et al, $2014^{8}$ & $U$ & $\mathrm{Y}$ & $\mathrm{N}$ & $\mathrm{Y}$ & $\mathrm{Y}$ & $\mathrm{Y}$ & $\mathrm{Y}$ & $\mathrm{Y}$ & $\mathrm{Y}$ & 7 \\
\hline $\begin{array}{l}\text { Salb et al, } \\
2015^{16}\end{array}$ & $\mathrm{~N}$ & $\mathrm{~N}$ & $\mathrm{Y}$ & $Y$ & $Y$ & $\mathrm{Y}$ & $\mathrm{Y}$ & $\mathrm{Y}$ & $\mathrm{Y}$ & 7 \\
\hline $\begin{array}{l}\text { Smulders et al, } \\
2013^{14}\end{array}$ & $\mathrm{~N}$ & $\mathrm{Y}$ & $\mathrm{Y}$ & $\mathrm{Y}$ & $\mathrm{Y}$ & $\mathrm{Y}$ & $\bar{Y}$ & $\mathrm{~N}$ & $\mathrm{Y}$ & 7 \\
\hline $\begin{array}{l}\text { Van Hanegem } \\
\text { et al, } 2014^{35}\end{array}$ & $\mathrm{~N}$ & $\mathrm{Y}$ & $\mathrm{Y}$ & $\bar{Y}$ & $\bar{Y}$ & $U$ & $U$ & $U$ & $\mathrm{Y}$ & 5 \\
\hline $\begin{array}{l}\text { Wagemans and } \\
\text { Cluitmans, } \\
2006^{5}\end{array}$ & $\mathrm{~N}$ & $\mathrm{~N}$ & $\mathrm{Y}$ & $\mathrm{N}$ & $\mathrm{Y}$ & $\bar{Y}$ & $\bar{Y}$ & $\bar{Y}$ & $\mathrm{Y}$ & 6 \\
\hline $\mathrm{Y \%}$ & 44.5 & 55.6 & 88.9 & 88.9 & 100 & 55.6 & 55.6 & 66.7 & 100 & \\
\hline Legend: & & & & & & & & & & \\
\hline
\end{tabular}


Q1: Was the sample frame appropriate to address the target population?

Q2: Were study participants sampled in an appropriate way?

Q3: Was the sample size adequate?

Q4: Were the study subjects and the setting described in detail?

Q5: Was the data analysis conducted with sufficient coverage of the identified sample?

Q6: Were valid methods used for the identification of the condition?

Q7: Was the condition measured in a standard, reliable way for all participants?

Q8: Was there appropriate statistical analysis?

Q9: Was the response rate adequate, and if not, was the low response rate managed appropriately? 


\section{Characteristics of included studies}

Characteristics of the nine included studies are shown in Appendix III. One of the nine included studies was a quasi-experimental study ${ }^{35}$ while the other eight used an observational design. Sample sizes ranged from $39^{35}$ to $1515^{7}$ participants and two studies had a higher proportion of female compared to male participants $\left(72.5 \%\right.$ and $75.5 \%$ being female). ${ }^{5,16}$ The mean age of participants was able to be calculated from eight studies and was 47.6 years. The age of participants in all nine studies ranged from 16 to 89 years. There were four studies that enrolled participants from one residential facility ${ }^{5,15-16,35}$ and five of the other studies had participants from a mixture of living arrangements 4,68,14 Seven studies used an observational period of 12 months, one study had an observational period of 33 months ${ }^{5}$ and one study had an average follow up period of four years and 5 months. ${ }^{15}$ Two studies only enrolled participants who had mild or moderate levels of ID, based on the rationale that participants would be required to understand the instructions to participate in baseline tests. ${ }^{14,35}$ One study excluded participants who had a diagnosis of epilepsy. ${ }^{14}$ Four studies collected falls data retrospectively and five studies collected falls data prospectively, either from daily records kept by completing monthly calendars ${ }^{14}$ or from falls incidence reports from accommodation support

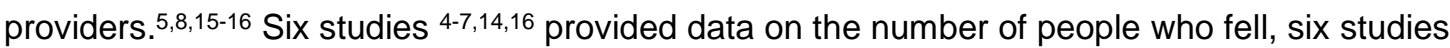
provided data on number of falls during the observation period.5,8,14-16,35 Only two studies specifically followed falls research recommendations ${ }^{17}$ by reporting falls rates. ${ }^{14,16}$ The remaining four studies provided data which allowed the rate of falls to be calculated. 5,8,15,35 Two studies reported on the number of injurious falls which allowed the injurious falls rate to be calculated. 5,16

\section{Findings of the review}

All the outcomes as outlined under the inclusion criteria were analyzed with the data extracted from the included studies. The findings are presented for the three outcomes of i) falls rates, ii) proportion of participants who experienced one or more falls and iii) falls that resulted in injuries (injurious falls rates).

\section{i) Falls Rates}

Six studies presented data which allowed the rate of falls to be calculated. The sample size, number of falls and the period of observation (months) and the falls rate for each of these studies are presented in Table 2. The falls rates ranged from 0.54 falls per person year ${ }^{15}$ (114 participants observed) to 6.29 falls per person year ${ }^{8}$ (28 participants observed).

\section{Table 2: Falls rates of included studies}

\begin{tabular}{|l|l|l|l|l|}
\hline Study & $\begin{array}{l}\text { Observation } \\
\text { period (months) }\end{array}$ & Sample $(\mathrm{n})$ & Falls $(\mathrm{n})$ & $\begin{array}{l}\text { Falls rates }^{\mathrm{a}}(\mathrm{per} \\
\text { person year) }\end{array}$ \\
\hline
\end{tabular}




\begin{tabular}{|c|c|c|c|c|}
\hline Salb et al, $2015^{16}$ & 12 & 147 & 140 & 0.95 \\
\hline Smulders et al, $2013^{14}$ & 12 & 82 & 77 & 1.06 \\
\hline Van Hanegem et al, $2014^{35}$ & 12 & 39 & 131 & 3.36 \\
\hline Wagemans and Cluitmans, $2006^{5}$ & 33 & 205 & 1200 & 2.13 \\
\hline bal et al, $2014(A)^{8}$ & 3 & 28 & 44 & 6.29 \\
\hline${ }^{b}$ Pal et al, $2014(B)^{8}$ & 6 & 33 & 39 & 2.37 \\
\hline${ }^{b}$ Pal et al, $2014(C)^{8}$ & 6 & 74 & 42 & 1.14 \\
\hline Grant et al, $2001^{15}$ & 507 person yrs ${ }^{c}$ & 114 & 275 & 0.54 \\
\hline
\end{tabular}

${ }^{a}$ Falls rates were calculated by taking number of falls/sample size and converting it to a 12 month period.

${ }^{\mathrm{b}} \mathrm{Pal}$ et al, 2014, reported on three different studies, each with a different cohort, the authors conducted in one publication. To calculate the falls rates data were separated and presented as results for study $A, B$ and $C$.

'Study did not report observational period for each participant but reported on the total number of person years available for follow up.

\section{ii) Proportion of participants who experienced one or more falls}

\section{Pooled Analysis}

Six studies that provided comparable statistics on the proportion/number of people with ID who experienced one or more falls during the study period were pooled for meta-analysis. Pooled results demonstrated that the proportion of people with ID who fell one or more times was $40 \%$ (Cl $0.27-$ 0.53). (See Figure 2). However there was a high degree of heterogeneity $\left(I^{2}=92.89 \%\right)$. 


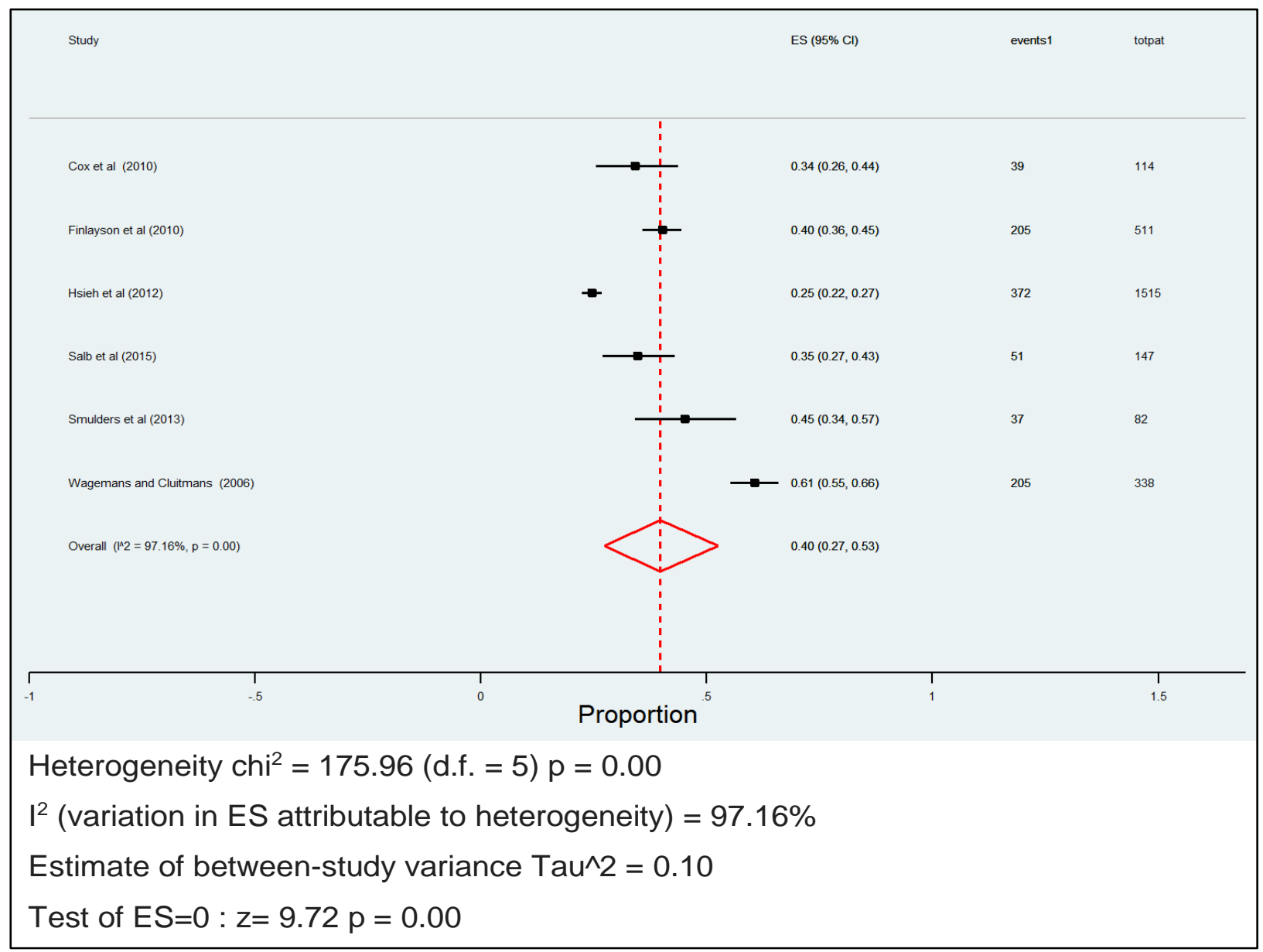

Figure 2: Meta-analysis of the proportion of people with ID who experienced one or more falls (six studies)

\section{Sensitivity Analysis}

Two ${ }^{5,7}$ of the six studies that reported data on the number of people who fell one or more times used methods that differed from the other four studies. One study had an observation period of 33 months, ${ }^{5}$ compared to the other five studies which observed participants for 12 months. ${ }^{4,6-7,14,16}$ One study collected falls data using a nationwide survey ${ }^{7}$ while the other five studies used interviews or organization based incidence reporting. When these two studies were removed from the metaanalysis, heterogeneity became low $\left(I^{2}=20.13 \%\right)$. Pooled results of the remaining four studies showed that the proportion of people with ID who fell one or more times was $39 \%$ ( $95 \% \mathrm{Cl} 0.35-0.43$ ) (Figure 3). 


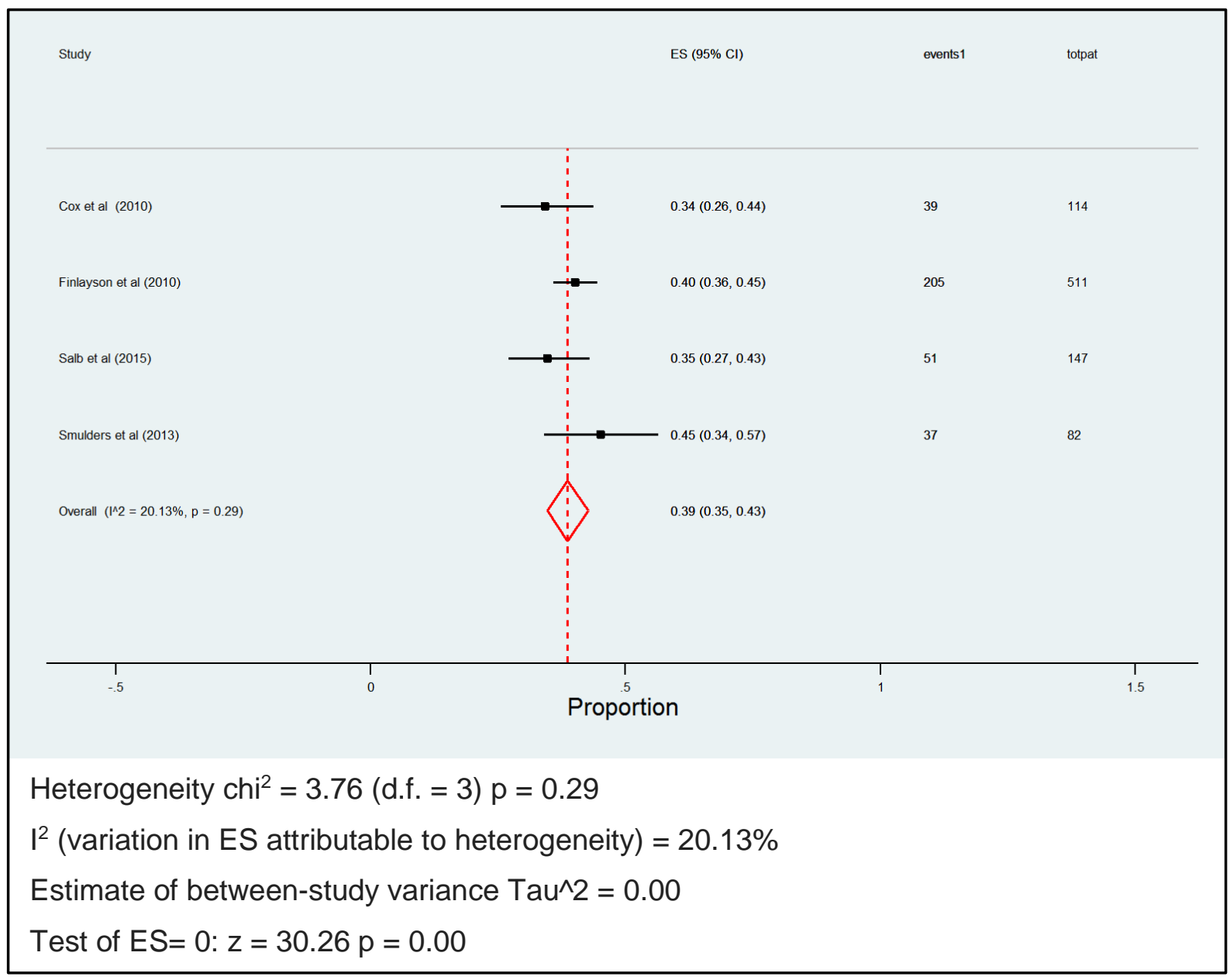

Figure 3: Meta-analysis of the proportion of people with ID who experienced one or more falls: sensitivity analysis based on falls data collection (four studies)

iii) Injurious falls

Two studies ${ }^{5,16}$ reported on the number of falls that resulted in one or more injuries (data presented in Table 3). The number of falls that resulted in one or more injuries was $48(34.3 \%)$ in the study conducted by Salb et al, $2015^{16}$ and $383(31.9 \%)$ in the study conducted by Wagamans and Cluitmans, 2006. ${ }^{5}$ These two studies also reported data which allowed the rate of injurious falls to be calculated. The incidence rate of injurious falls ranged from 0.33 to 0.68 per person year (presented in Table 2). However, these studies differed, with Wagamans and Cluitmans, 2006 study period being 33 months while Salb et al, $2015^{15}$ used a 12 month observational period. Therefore, the data reporting the number of people who fell in these two studies were not appropriate to pool in a metaanalysis. The other studies $4,6-8,14-16,35$ did not provide data that allowed an injurious falls rate to be calculated. Grant et al, $2001^{15}$ reported that $78.5 \%$ of falls resulted in injuries but did not report the actual number of injurious falls and therefore was not included in Table 3. 
Table 3: Injurious falls rates of included studies

\begin{tabular}{|l|c|c|c|c|}
\hline Study & $\begin{array}{c}\text { Observation } \\
\text { period (months) }\end{array}$ & Sample (n) & $\begin{array}{c}\text { Number of } \\
\text { injurious falls }(\mathrm{n})\end{array}$ & $\begin{array}{c}\text { Injurious falls rates } \\
\text { (per person yr) }\end{array}$ \\
\hline Salb et al, 2015 & 12 & 147 & 48 & 0.33 \\
\hline $\begin{array}{l}\text { Wagemans and } \\
\text { Cluitmans, 20065 }\end{array}$ & 33 & 205 & 383 & 0.68 \\
\hline
\end{tabular}

alnjurious falls rates were calculated by taking number of falls that resulted in one or more injuries and the observation period for each participant to calculate the incidence rate of injurious falls per person period. Each study result was converted to a rate of injurious falls per person year for comparison.

\section{GRADE Certainty Assessment and Results}

The certainty of the evidence presented in each of the studies used in the systematic analysis of all three outcomes were assessed using the GRADE approach. ${ }^{40}$ The certainty of evidence was graded as very low in all three of the outcomes. The risk of bias was rated serious for all groups of studies used in all three outcomes.

Inconsistency was rated depending on the heterogeneity of the study design, data collection, the participants' age group and living arrangements. For the outcome of Proportion of Participants Who Experienced One or More Falls, inconsistency was rated as low. Inconsistency was rated as low for the outcome of Rate of Injurious Falls because the study design and data collection were similar, which enabled injurious falls rates to be calculated from the number of injuries provided in included studies. Inconsistency was rated as very serious for the outcome of Falls Rates.

Imprecision for the studies was rated serious to very serious for all of the outcomes and publication bias was strongly suspected.

\section{DISCUSSION}

The aim of this review was to investigate the prevalence and incidence of falls in adults with ID living in community based settings. After an extensive search and quality assessments of the studies, nine studies were included in the systematic review, of which six were used to contribute data to metaanalyses.

\section{Meta-Analysis}

The pooled analysis of the studies found that the proportion of people with ID who fell during the study observation period was $39 \%$ (ranging from $35 \%$ to $43 \%$ ). This compares with previous large studies ${ }^{1,41}$ conducted in community populations which found that approximately $30 \%$ to $40 \%$ of people 65 years and over, fall in a 12 month period, with approximately $50 \%$ of people over the age of 80 years old falling in a 12 month period. The mean age of the participants in this review was 47.6 years, indicating that people with ID experience a high prevalence of falls at a younger age compared to the general community where falls are not considered a problem until people are aged 65 years and over. 
Therefore, it is important for health professionals to note that falls prevention is highly relevant when providing healthcare to people with ID throughout their adult life, rather than delaying such interventions until they are over the age of 65 years. People with ID are highly likely to benefit from falls prevention services that are designed in a similar way to falls services for older people, ${ }^{42}$ with additional tailoring for individual needs. ${ }^{3}$

Nine of 22 studies investigating falls among people with ID identified were screened as appropriate to be included the review. It was not possible to pool data from all nine studies to determine the overall prevalence and incidence of falls for adults with ID living in the community because the study populations (age groups, living arrangements) differed, as did the study designs. The number of studies and the data they reported were limited, hence we were unable to report falls rates for any particular subgroup such as age groups. Therefore this review was only able to provide data for adults with ID as a homogenous sample.

There was also a wide variation of falls rates ranging from 0.54 to 6.29 falls per person year. This may not be an accurate representation of the true incidence rates of falls in this population, as individual study results were not consistently higher or lower than reported falls rates within the older population, which are estimated at 0.74 per person year. ${ }^{33}$ It was not possible to determine if the variation was entirely due to heterogeneity in population differences or study reporting. For example, low and high falls rates were found in studies that had participants living in residential as well as mixed living arrangements. Studies that collected falls data using recommended methods (prospective data collection) also reported a wide range of falls rates.

\section{Quality of Studies}

This review also aimed to investigate injurious falls rates. However only two studies, provided data on injurious falls (falls that resulted in an injury or injuries) and two separate studies 5,16 reported the number of people who sustained a an injury as a result of a fall. These data were not able to be pooed in meta-analysis to report on the number of people sustaining an injurious fall or a pooled incidence rate of injurious falls.

\section{Quality of Evidence}

The risk of bias using the GRADE Approach ${ }^{40}$ was rated serious for all groups of studies as less than $50 \%$ of the studies did not have a sample frame that clearly addressed the target population and four out of nine studies either recruited participants from only one residential setting ${ }^{5,15-16}$ or recruited participants who responded to an online or posted survey. ${ }^{7}$ Inconsistency was rated depending on the heterogeneity of the study design, data collection and the participant's age group and living arrangements. In the outcome Proportion of Participants Who Experienced One or More Falls, the inconsistency was rated low, as a sensitivity analysis was carried out based on studies with similar study design. Falls data were collected prospectively from residential facilities or from care staff of service providers who had direct contact with the participants and observation period was 12 months in the included studies. Inconsistency was also low in the outcome Rate of Injurious Falls as the study design and data 
collection was similar which enabled the calculation of injurious falls rates possible from the number of injuries provided in included studies. Inconsistency was rated as very serious for Falls Rates as estimated falls rates varied widely and showed inconsistent variance when compared to the fall rates of community or nursing home dwelling older people (known to be approximately 0.74 falls $^{33}$ in the community and 3.6 falls ${ }^{43}$ per person year in nursing home settings). Imprecision for the studies were rated serious to very serious for the outcomes.

The confidence interval across the four studies used in the outcome Proportion of Participants Who Experienced One or More Falls ranged from $26 \%$ to $57 \%$, indicating a high degree of uncertainly of the weighted effect size at $39 \%$. The range of reported falls and the injurious falls rates from all included studies in the review was wide, therefore the results were considered imprecise for the population.

Publication bias is strongly suspected in this systematic review as authors found a poster abstract reporting the prevalence of falls in older adults with ID residing in Ireland, ${ }^{44}$ however none of the studies included in this review were from Ireland. The studies included were also from one facility in Germany ${ }^{15}$ or from a single regional area in United Kingdom. ${ }^{6}$ There is also a large proportion of people living with ID worldwide who have not been included in the studies.

\section{Limitations}

Only six studies were included in the meta-analysis, out of which four were included in the sensitivity analysis, therefore the results need to be interpreted cautiously. Furthermore, due to the limited number of studies, it was necessary to combine studies which investigated the prevalence and/or incidence of falls in adults with ID living in community based as well as residential settings. Therefore the results obtained from the pooled analysis for fallers were not limited to people with ID living in community based settings as we stated our published protocol. ${ }^{25}$ Patient characteristics such as muscle weakness, mobility status and cognitive impairment have been shown to affect the risk of falls. There were insufficient data to conduct these types of subgroup analyses. ${ }^{1}$ It was also not possible to pool the incidence rates of falls because patient level data were not presented and neither were data which would allow an estimate of the degree of uncertainty of the incidence rate reported. Individual patient data for each study would be ideal to conduct this meta-analysis in the future.

Researchers should also note that analysis of the studies using the JBI GRADE ${ }^{40}$ criteria showed that the evidence pooled from the included studies were of very low quality and therefore should caution the interpretation of the results.

\section{Conclusion}

There was a high level of heterogeneity between the included studies, making it challenging to compare the outcomes of interest. This systematic review found that $39 \%$ adults with ID fall once or more in a 12 month period (very low certainty of GRADE evidence ${ }^{40}$ ). This prevalence is reported at a younger age when compared to the prevalence of falls in the broad community dwelling population. Falls rates ranged widely from 0.54 to 6.29 falls per person year, with unexplained heterogeneity. Based on the limited data, the review was not able to estimate the prevalence of injurious falls. We 
recommend that more high quality research regarding falls incidence in people with ID is conducted in accordance with recommended guidelines.

\section{Recommendations for practice}

The finding of this review suggest that falls become a health problem for people with ID at an earlier age in life compared to the general community-dwelling population and that the prevalence of falls remains high throughout their adult life. Health practitioners should consider regular assessments, management of falls risk and provision of falls interventions for all adults with ID and their care providers. In particular they should be aware that falls management may need to commence at an earlier age by including adults with ID who are approaching the age of 40 years, rather than commencing falls management when they are over 60 years of age. This approach varies from population falls guidelines for general community populations that direct their recommendations towards people who are 65 years of age and older. ${ }^{27,45}$

\section{Recommendations for research}

The uncertainty of the true prevalence and incidence of falls and injurious falls among people with ID is a serious limitation for both researchers and health care services. Robust trials that evaluate the effectiveness of falls prevention interventions for people with ID are urgently required. To conduct these efficacy studies, accurate measurement of falls outcomes is critical and additionally researchers need to accurately estimate sample sizes required. There are currently high levels of variability in the studies conducted to measure falls rates in this population, making estimates uncertain. This is a critical gap as injuries resulting from falls are a significant problem in older populations, ${ }^{4-5}$ therefore more studies are needed to evaluate the extent of this problem among people with ID.

There are challenges in conducting falls research with people with ID and further work is required to develop methodology for adhering to guidelines for conducting falls research among people with ID. Health care services also need to understand the true extent of the problem of falls and injurious falls among people with ID, to appropriately deliver targeted resources and services. 


\section{REFERENCES}

1. Rubenstein LZ. Falls in older people: epidemiology, risk factors and strategies for prevention. Age Ageing. 2006;35(Suppl):ii37-41.

2. Australian Commission on Safety and Quality in Healthcare (ACSQHC). Preventing falls and harm from falls in older people. 2009 [Internet]. 2009 Aug. [Cited 2017 Nov 18]. Available from: https://www.safetyandquality.gov.au/wp-content/uploads/2012/01/Guidelines-

COMM.pdf

3. Smulders E, Enkelaar L, Schoon Y, Geurts AC, van Schrojenstein Lantman-de Valk H, Weerdesteyn V. Falls prevention in persons with intellectual disabilities: Development, implementation, and process evaluation of a tailored multifactorial fall risk assessment and intervention strategy. Res Dev Disabil. 2013; 34(9):2788-98.

4. Cox CR, Clemson L, Stancliffe RJ, Durvasula S, Sherrington C. Incidence of and risk factors for falls among adults with an intellectual disability. J Intellect Disabil Res. 2010; 54(12):104557.

5. Wagemans AMA, Cluitmans JJM. Falls and fractures: A major health risk for adults with intellectual disabilities in residential settings. J Policy Pract Intellect Disabil. 2006;3(2):136-8.

6. Finlayson J, Morrison J, Jackson A, Mantry D, Cooper SA. Injuries, falls and accidents among adults with intellectual disabilities. Prospective cohort study. J Intellect Disabil Res. 2010;54(11):966-80.

7. Hsieh K, Rimmer J, Heller T. Prevalence of falls and risk factors in adults with intellectual disability. Am J Intellect Dev Disabil. 2012;117(6):442-54.

8. Pal J, Hale L, Mirfin-Veitch B, Claydon L. Injuries and falls among adults with intellectual disability: A prospective New Zealand cohort study. J Intellect Dev Disabil. 2014;39(1):35-44.

9. American Psychiatric Association. Diagnostic and statistical manual of mental disorders. $5^{\text {th }}$ ed. Arlington,US: American Psychiatric Publishing; 2013.

10. Willgoss TG, Yohannes AM, Mitchell D. Review of risk factors and preventative strategies for falls-related injuries in people with intellectual disabilities. J Clin Nurs. 2010;19(15-16):2100-9.

11. Cahill S, Stancliffe RJ, Clemson L, Durvasula S. Reconstructing the fall: Individual, behavioural and contexual factors associated with falls in individuals with intellectual disability. J Intellect Dev Disabil. 2014;58(4):321-32.

12. Carmeli E, Iman B, Bachar A, Merrick J. Inflammation and oxidative stress as biomarkers of premature aging in person with intellectual disability. Res Dev Disabil. 2011; 33(2):369-75.

13. Strydom A, Shooshtari S, Lee L, Raykar V, Torr J, Tsiouris J, et al. Dementia in older adults with intellectual disabilities - epidemiology, presentation, and diagnosis. J Policy Pract Intellect Disabil. 2010;7(2):96-110.

14. Smulders E, Enkelaar L, Weerdesteyn V, Geurts AC, Schrojenstein Lantman-de Valk H. Falls in older persons with intellectual disabilities: fall rate, circumstances and consequences. $J$ Intellect Disabil Res. 2013;57(12):1173-82. 
15. Grant HJ, Pickett W, Lam M, O'Connor M, Ouellette-Kuntz H. Falls among persons who have developmental disabilities in institutional and group home settings. J Dev Disabl. 2001;8(1):57-73.

16. Salb J, Woodward C, Offenhäußer J, Becker C, Sieber C, Freiberger E. Prevalence and characteristics of falls in adults with intellectual disability living in a residential facility: A longitudinal study [PreFallID]. Intellect Dev Disabil. 2015;53(3):228-39.

17. Lamb SE, Jørstad-Stein EC, Hauer K, Becker C. Development of a common outcome data set for fall injury prevention trials: The prevention of falls network europe consensus. J Am Geriatr Soc. 2005;53(9):1618-22.

18. McDonald KE, Kidney CA. What is right? Ethics in intellectual disabilities research. J Policy Pract Intellect Disabil. 2012;9(1):27-39.

19. Lennox N, Taylor M, Rey-Conde T, Bain C, Purdie DM, Boyle F. Beating the barriers: recruitment of people with intellectual disability to participate in research. J Intellect Disabil Res 2005;49(4):296-305.

20. Hauer K, Lamb SE, Jorstad EC, Todd C, Becker C, PROFANE-Group. Systematic review of definitions and methods of measuring falls in randomised controlled fall prevention trials. Age Ageing. 2006;35(1):5-10.

21. Kwan MM-S, Close JCT, Wong AKW, Lord SR. Falls incidence, risk factors, and consequences in Chinese older people: a systematic review. J Am Geriatr Soc. 2011;59(3):536-43.

22. Enkelaar L, Smulders E, van Schrojenstein Lantman-de Valk H, Geurts A, Weerdesteyn V. A review of balance and gait capacities in relation to falls in persons with intellectual disability Res Dev Disabil. 2012;33(1):291-306.

23. Sherrard J, Ozanne-Smith J, Staines C. Prevention of unintentional injury to people with intellectual disability: a review of the evidence. J Intellect Disabil Res. 2004;48(7):639-45.

24. Heinrich S, Rapp K, Rissmann U, Becker C, König HH. Cost of falls in old age: a systematic review. Osteoporos Int. 2010;21(6):891-902.

25. Ho P, Patman S, Bulsara C, Downs J, Bulsara M, Hill A-M. Incidence and prevalence of falls in adults with intellectual disability living in the community: a systematic review protocol. JBI Database System Rev Implement Rep. 2017;15(7):1819-23.

26. Richmond DT. Inquiry into Health Services for the psychiatrically ill and developmentally disabled. Department of Health, N.S.W: State Health Publication No. (DP 83-020); 1983. Part 2:p9.

27. World Health Organization. Global report on falls prevention in older age [Internet]. Geneva: World Health Organization; 2007 Feb [Cited Oct 21, 2017]. Available from: http://www.who.int/ageing/projects/falls_prevention_older_age/en/index.html

28. Hill A-M, Hoffmann T, McPhail S, Beer C, Hill KD, Oliver D, et al. Evaluation of the sustained effect of inpatient falls prevention education and predictors of falls after hospital discharge-follow-up to a randomized controlled trial. J Gerontol A Biol Sci Med Sci. 2011;66(9):1001-12. 
29. Munn Z, Moola S, Lisy K, Riitano D, Tufanaru C. Methodological guidance for systematic reviews of observational epidemiological studies reporting prevalence and cumulative incidence data. Int J Evid Based Healthc. 2015;13(3):147-53.

30. Gillespie LD, Robert MC, Gillespie WJ, Sherrington C, Gates S, Clemson LM, et al. Interventions for preventing falls in older people living in the community. Cochrane Database Syst Rev 2012:CD007146.

31. Goodwin VA, Abbott RA, Whear R, Bethel A, Ukoumunne OC, Thompson-Coon J, et al. Multiple component interventions for preventing falls and fall-related injuries among older people: systematic review and meta-analysis. BMC Geriatr. 2014;14:15.

32. Carpenter GI, Demopoulos GR. Screening the elderly in the community: controlled trial of dependency surveillance using a questionnaire administered by volunteers. BMJ (Clinical Research Ed). 1990;300(6734):1253-6.

33. Campbell AJ, Borrie MJ, Spears GF, Jackson SL, Brown JS, Fitzgerald JL. Circumstances and consequences of falls experienced by a community population 70 years and over during a prospective study. Age Ageing. 1990;19(2):136-41.

34. Joanna Briggs Institute's System for the Unified Management, Assessment and Review of Information (JBI-SUMARI). Version 5, 2016 [cited 2017, Oct 14]. Available from https://www.jbisumari.org

35. Van Hanegem E, Enkelaar L, Smulders E, Weerdesteyn V. Obstacle course training can improve mobility and prevent falls in people with intellectual disabilities. J Intellect Disabili Res. 2014;58(5):485-92.

36. Nyaga VN, Arbyn M, Aerts M. Metapop: a Stata commod to perform meta-analysis of binomial data. Arch Public Health. 2014;72 (1):39.

37. Miller JJ. The inverse of the freeman-tukey double arcsine transformation. Am Stat. 1978;32(4): 138.

38. Higgins JP, Thompson SG, Deeks JJ, Altman DG. Measuring inconsistency in meta-analyses. BMJ. 2003;327(7414):557-60.

39. Moher D, Liberati A, Tetzlaff J, Altman DG. Preferred reporting items for systematic review and meta-analysis: The PRISMA statement. Int J Surg. 2010;8(5):336-41.

40. The Joanna Briggs Institue. GRADE Handbook: Handbook for grading the quality of evidence and the strength of recommendations using the GRADE approach. Australia: The Joanna Briggs Institute; 2013 [cited 2017 Nov 14]. Availabel from: https://gradepro.org/handbook/

41. Milat AJ, Watson WL, Monger C, Barr M, Giffin M, Reid M. Prevalence, circumstances and consequences of falls among community-dwelling older people: results of the $2009 \mathrm{NSW}$ Falls Prevention Baseline Survey. N S W Public Health Bull. 2011;22(3-4):43-8.

42. Feder G, Cryer C, Donovan S, Carter Y. Guidelines for the prevention of falls in people over 65. BMJ. 2000;321(7267):1007-1011.

43. Rubenstein LZ, Josephson KR, Robbins AS. Falls in the nursing home. Ann Intern Med. 1994; 121(6):442-51. 
44. Foran S, McCallion P, McCarron M. The Prevalence of falls among older adults with intellectual disability in Ireland. Age Ageing. 2016;45 (suppl_2) :ii13-ii56.

45. Centers for Disease Control and Prevention (CDC): Take a stand on falls. [Internet]. 2017 Sept 22 [cited 2018, Sept 1]. Available from: https://www.cdc.gov/features/older-adultfalls/index.html 
Appendix I: Search Strategy of Databases Note: all searches date range was from 1990 to

December $31^{\text {st }} 2017$ (Search date $-7^{\text {th }}$ March 2018)

\section{MEDLINE (OVID)}

Database: Ovid MEDLINE(R) Epub Ahead of Print, In-Process \& Other Non-Indexed Citations, Ovid MEDLINE(R) Daily, Ovid MEDLINE and Versions(R) <1946 to March 07 2018>

Search Strategy:

1 exp Accidental Falls/ (20295)

2 fall\$.mp. [mp=title, abstract, original title, name of substance word, subject heading word, keyword heading word, protocol supplementary concept word, rare disease supplementary concept word, unique identifier, synonyms] (220031)

3 fall prevention.mp. [mp=title, abstract, original title, name of substance word, subject heading word, keyword heading word, protocol supplementary concept word, rare disease supplementary concept word, unique identifier, synonyms] (2034)

4 exp Intellectual Disability/ (89749)

5 exp developmental disabilities/ (17951)

6 exp learning disorders/ (20894)

7 intellectual disabilit\$.mp. [ $\mathrm{mp}=$ title, abstract, original title, name of substance word, subject heading word, keyword heading word, protocol supplementary concept word, rare disease supplementary concept word, unique identifier, synonyms] (58446)

8 developmental disabilit*. $\mathrm{mp}$. [mp=title, abstract, original title, name of substance word, subject heading word, keyword heading word, protocol supplementary concept word, rare disease supplementary concept word, unique identifier, synonyms] (20715)

9 learning disabilit\$.mp. [mp=title, abstract, original title, name of substance word, subject heading word, keyword heading word, protocol supplementary concept word, rare disease supplementary concept word, unique identifier, synonyms] (7439)

10 mental retard ${ }^{*} . \mathrm{mp}$. [mp=title, abstract, original title, name of substance word, subject heading word, keyword heading word, protocol supplementary concept word, rare disease supplementary

concept word, unique identifier, synonyms] (28252)

114 or 5 or 6 or 7 or 8 or 9 or $10(144180)$

121 or 2 or $3(220031)$

1311 and $12(1142)$

14 limit 13 to ("young adult (19 to 24 years)" or "adult (19 to 44 years)" or "young adult and adult (19-24 and 19-44)" or "middle age (45 to 64 years)" or "middle aged (45 plus years)" or "all aged (65 and over)" or "aged (80 and over)") (368)

15 limit 14 to $y r=" 1990-2017 "$ (287)

CINAHL

\begin{tabular}{|c|c|c|c|}
\hline Search Terms & Search Options & Actions & Results \\
\hline S4 & $\begin{array}{l}\left.\text { (TX accidental fall }{ }^{\star}\right) \text { AND } \\
\text { (S1 AND S2) }\end{array}$ & $\begin{array}{l}\text { Limiters - Published } \\
\text { Date: } 19900101- \\
\text { 20171231; Age } \\
\text { Groups: Adult: } 19-44 \\
\text { years, Middle Aged: } \\
\text { 45-64 years, Aged: } \\
\text { 65+ years } \\
\\
\text { Search modes - } \\
\text { Boolean/Phrase }\end{array}$ & View Results (67) \\
\hline S3 & $\begin{array}{l}\left(\text { TX accidental fall }{ }^{\star} \text { AND }\right. \\
(\text { S1 AND S2) }\end{array}$ & $\begin{array}{l}\text { Search modes - } \\
\text { Boolean/Phrase }\end{array}$ & View Results (125) \\
\hline S2 & TX accidental fall ${ }^{*}$ & $\begin{array}{l}\text { Search modes - } \\
\text { Boolean/Phrase }\end{array}$ & View Results $(17,430)$ \\
\hline S1 & $\begin{array}{l}\text { TX intellectual disability or } \\
\text { mental retardation or } \\
\text { learning disability or } \\
\text { developmental disability or } \\
\text { learning disabilities }\end{array}$ & $\begin{array}{l}\text { Search modes - } \\
\text { Boolean/Phrase }\end{array}$ & View Results $(67,974)$ \\
\hline
\end{tabular}




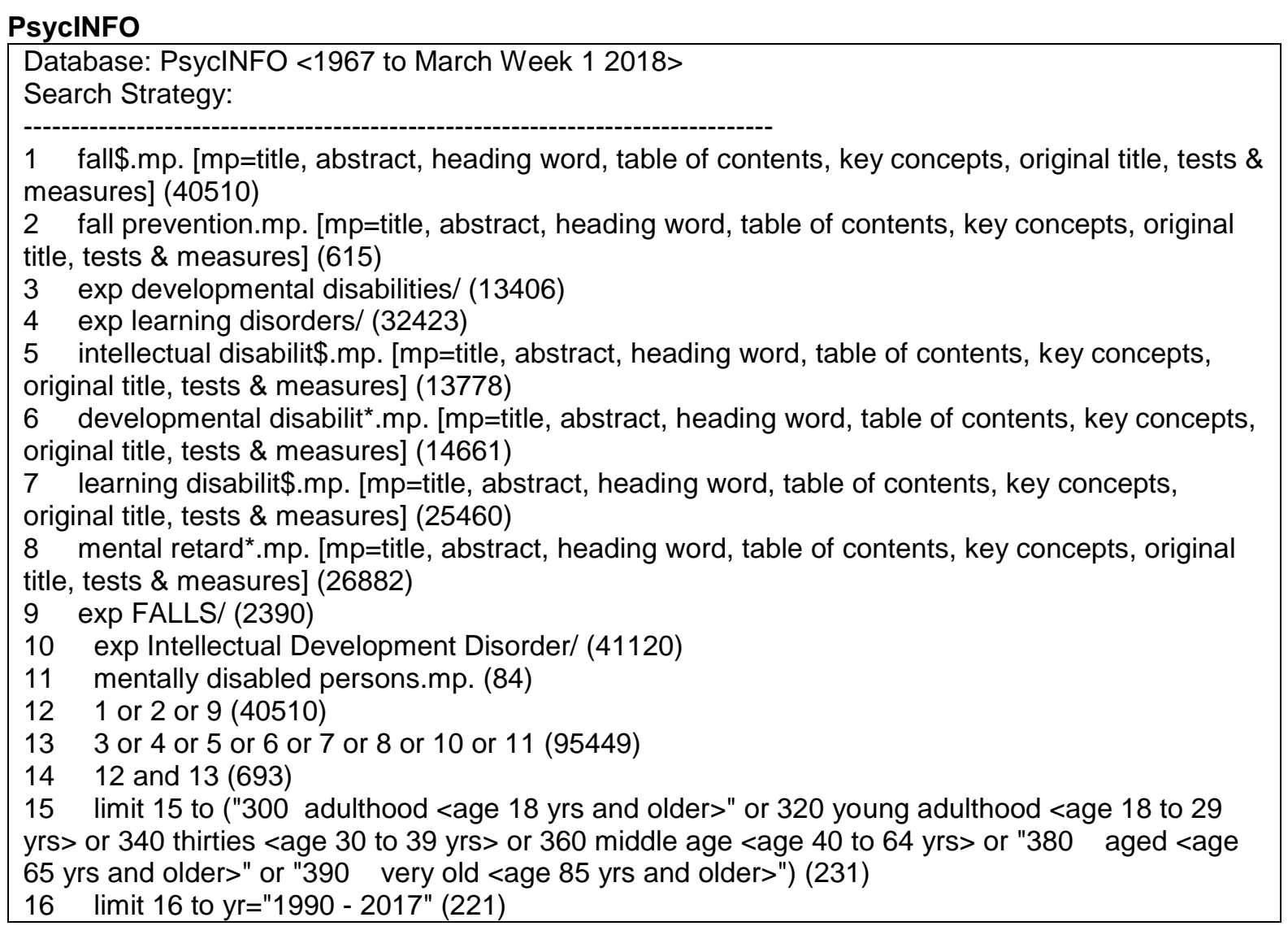

AMED

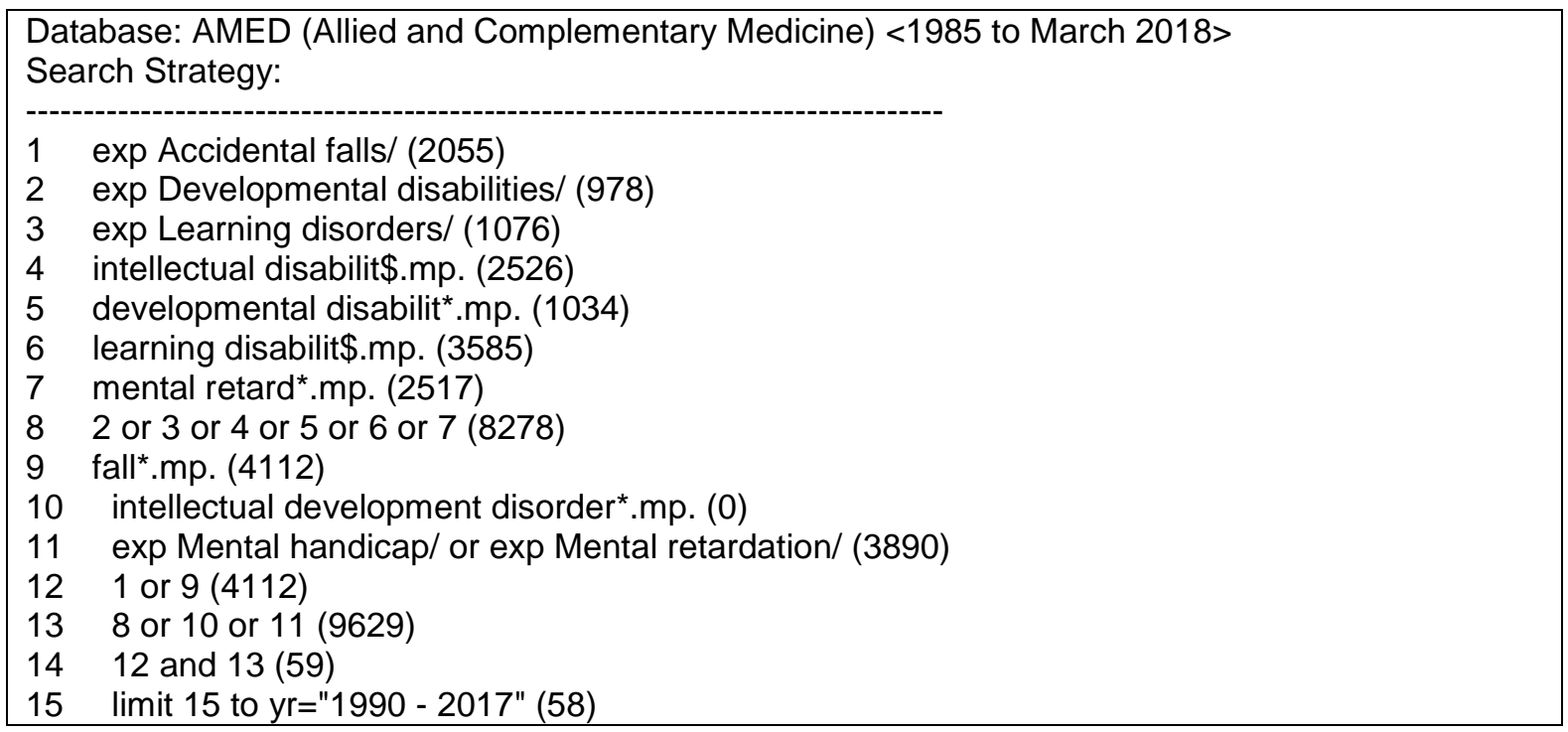

\section{EMBASE}

Database: Embase <1974 to 2018 March 07>

Search Strategy:

1 exp Accidental Falls/ (34290)

2 fall $\$ \mathrm{mp}$. [mp=title, abstract, heading word, drug trade name, original title, device manufacturer, drug manufacturer, device trade name, keyword, floating subheading word] (272563)

3 fall prevention.mp. [mp=title, abstract, heading word, drug trade name, original title, device manufacturer, drug manufacturer, device trade name, keyword, floating subheading word] (2599)

4 exp Intellectual Disability/ (449879) 


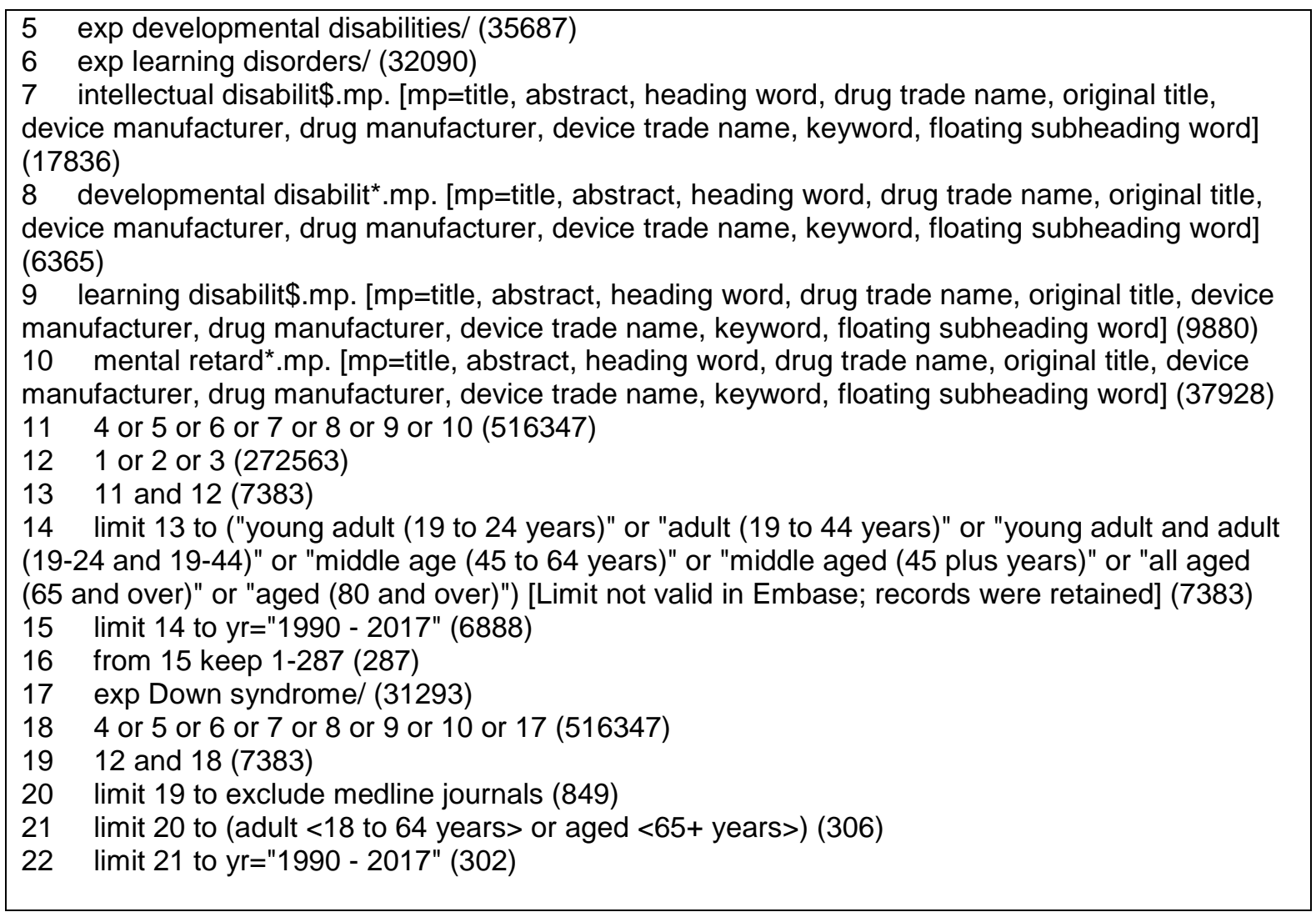

\section{Cochrane Library}

\begin{tabular}{|lll|}
\hline ID & Search Hits & \\
$\# 1$ & MeSH descriptor: [Accidental Falls] explode all trees & 1433 \\
$\# 2$ & MeSH descriptor: [Accidental Falls] this term only & 1433 \\
$\# 3$ & "Falls" or "Faller":ti,ab,kw (Word variations have been searched) 18558 \\
$\# 4$ & $\# 1$ or \#2 $\quad 1433$ & \\
$\# 5$ & MeSH descriptor: [Intellectual Disability] this term only & 675 \\
$\# 6$ & "learning disability" or "developmental disability" or "mental retardation":ti,ab,kw (Word \\
variations have been searched) 1588 & \\
$\# 7$ & $\# 5$ or \#6 $\quad 2073$ & \\
$\# 8$ & $\# 4$ and \#7 $\quad 2$ & \\
$\# 9$ & MeSH descriptor: [Developmental Disabilities] this term only & 566 \\
$\# 10$ & $\# 5$ or \#6 or \#9 & 2073 \\
$\# 11$ & $\# 1$ or \#3 & 18558 \\
$\# 12$ & $\# 10$ and \#11 & 27 \\
\hline
\end{tabular}

\section{Current Controlled Trials (http://www.isrctn.com)}

Text Search: Falls

Condition: Mental and behavioural disorder

Limiters: Adults, Completed trials

Results $=37$

\section{National Institute of Health Clinical Database (http://www.cliniclaltrials.gov), searched}

Advance Search: Limiters Age 18 and over, Year of publication: 1990-2017

Condition: Fall, Other terms: Intellectual disability OR Learning Disability OR Developmental Disability

OR Mental Retardation $=7$ 
TROVE

\begin{tabular}{|l|l|l|}
\hline Search & Query & Results \\
\hline$\# 1$ & $\begin{array}{l}\text { Keyword: Falls } \\
\text { Title: Falls* AND Intellectual Disability* }\end{array}$ & 7 \\
\hline$\# 2$ & $\begin{array}{l}\text { Keyword: Falls } \\
\text { Title: Falls* AND Developmental Disability* }\end{array}$ & 1 \\
\hline$\# 3$ & $\begin{array}{l}\text { Keyword: Falls } \\
\text { Title: Falls* AND Learning Disability* }\end{array}$ & 0 \\
\hline $\begin{array}{l}\text { Keyword: Falls } \\
\text { Title: Falls* AND Learning Disability* }\end{array}$ & 2 \\
\hline Limiters - published date: $1990-2017$, Age: adults & \\
\hline Total $=10$ &
\end{tabular}

\section{Google Scholar}

"falls in people with intellectual disabilities" = 32

"falls in people with learning disabilities" $=8$

"falls in people with mental retardation" $=0$

"falls in people with developmental disabilities" $=0$

"prevalence of falls" AND intellectual disability $=85$

"incidence of falls" AND intellectual disability $=3270$

ProQuest Theses and Dissertations $7^{\text {th }}$ March 2018

\begin{tabular}{|c|c|c|}
\hline Search & Query & Results \\
\hline$\# 1$ & noft(falls*) & 9798 \\
\hline \#2 & noft (accidental falls) & 138 \\
\hline \#3 & noft (falls AND falls prevention) & 929 \\
\hline \#4 & $\begin{array}{l}\text { noft (accidental falls) OR noft (falls AND falls prevention) OR noft } \\
\left.\text { (falls }{ }^{\star}\right)\end{array}$ & 10397 \\
\hline$\# 5$ & (noft (intellectual disability) & 2048 \\
\hline \#6 & noft (developmental disability) & 4776 \\
\hline$\# 7$ & noft (learning disorder) & 5390 \\
\hline$\# 8$ & noft (mental retardation) & 3140 \\
\hline$\# 9$ & noft (intellectually disabled) & 162 \\
\hline$\# 10$ & noft (intellectually impaired) & 42 \\
\hline$\# 11$ & $\begin{array}{l}\text { (noft (intellectual disability) OR noft (developmental disability) OR } \\
\text { noft (learning disorder) OR noft (mental retardation)) OR noft } \\
\text { (intellectually disabled) OR noft (intellectually impaired)) }\end{array}$ & 12600 \\
\hline$\# 12$ & $\begin{array}{l}\text { (((noft (intellectual disability) OR noft (developmental disability) OR } \\
\text { noft (learning disorder) OR noft (mental retardation)) OR noft }\end{array}$ & 25 \\
\hline
\end{tabular}




\begin{tabular}{|l|l|l|}
\hline & $\begin{array}{l}\text { (intellectually disabled) OR noft (intellectually impaired)) AND } \\
((\text { noft(accidental falls) OR noft (falls AND falls prevention)) OR noft } \\
(\text { falls }))\end{array}$ & \\
\hline \multicolumn{2}{|l|}{ Limiters - Language: English, Published date: $1990-2017$, Age: adults } \\
\hline
\end{tabular}

\section{Rehabilitation Research and Training Center on Developmental Disabilities and Health (rrtcadd.org), Centre for Developmental Disability Health Victoria (www.cddh.monash.org), Centre for Applied Disability Research (www.cadr.org.au). Searched through all current and published research projects. $=0$}

\section{Appendix II: Studies excluded on full-text}

Crockett J, Finlayson J, Skelton DA, Miller G. Promoting exercise as part of a physiotherapy - led falls pathway service for adults with intellectual disabilities: a service evaluation. J Appl Res Intellect Disabil. 2015;28:257-64

Reason for exclusion: The outcome of interest was not clearly documented. The focus of the study was not to investigate incidence/prevalence of falls.

Enkelaar L,Smulders E, van Schrojenstein Lantman-de Valk H, Weerdesteyn V, Geurts AC. Prospective study on risk factors for falling in elderly persons with mild to moderate intellectual disabilities. Res Dev Disabil. 2013;34 3745-65

Reason for exclusion: The focus of the study was the risk factors for falls and falls rates were not the focus of the study. Therefore the outcomes of interest was not reported clearly.

Finlayson J, Morrison J, Skelton DA, Ballinger C, Mantry D, Jackson A, Cooper SA. The circumstances and impact of injuries on adults with learning disabilities. $\mathrm{Br} \mathrm{J}$ Occup Ther. 2014;77(8):400-9

Reason for exclusion: This paper describes the same population used in an included study and falls rates were not the outcomes of interest in this study.

Hale LA, Mirfin-Veitch BF and Treharne GJ. Prevention of falls for adults with intellectual disability (PROFAID): a feasibility study. J Intellect Disabil Res. 2007; 51: 260-8

Reason for exclusion: The focus of this study was to measure the outcome of a falls prevention program. None of the outcomes reported were specific to falls rates.

Hsieh K, Heller T and Miller AB. Risk factors for injuries and falls among adults with developmental disabilities. J Intellect Disabil Res. 2001;45(1):76-82

Reason for exclusion: The focus of the study was the risk factors for falls and falls rates were not the focus of the study. Therefore the outcomes of interest was not reported clearly.

Schoufour JD, Echteld MA, Bastiaanse LP, Evenhuis HM. The use of frailty index to predict adverse health outcomes (falls, fractures, hospitalization, medication use, comorbid conditions) in people with intellectual disabilities. Res Dev Disabil. 2015; 38: 39-47 
Reason for exclusion: The outcome of interest was not clearly documented Sherrard J, Tonge BJ, Ozanne-Smith J. Injury in young people with intellectual disability: descriptive epidemiology. Inj Prev. 2001; 7: 56-61

Reason for exclusion: This study collected epidemiological data on the number of injuries in people with ID. Falls data were reported in relation to the injuries sustained and not as the main focus of the study. Outcomes of interest were not documented clearly.

Strauss D, Shavelle R, Anderson TW, Baumeister A. External causes of death among persons with developmental disability: The effect of residential placement. Am J Epidemiol. 1998;147(9):855-62.

Reason for exclusion: The focus of this study was to look at causes of death. Falls were only recorded if it caused death. Therefore outcome of interest was not reported. Oppewal A, Hilgenkamp TIM, van Wijck R, Schoufour JD, Evenhuis HM. The predictive value of physical fitness for falls in older adults with intellectual disability. Res Dev Disabil. 2014;35:1317-25

Reason for exclusion: The outcome of interest was not documented clearly. Morgan PE, McGinley JL. Falls, fear of falling and falls risk in adults with cerebral palsy: A pilot observational study. Eur J Physiother. 2013;15(2):93-100

Reason for exclusion: Study included participants with Cerebral Palsy and not ID. The Abbreviated Mental Test score was used to score level of cognitive impairment. It was not clear if the subjects had intellectual disability fulling the DSM-5 criteria.

Bruckner J, Herge, EA. Assessing the risk of falls in elders with mental retardation and developmental disabilities. Top Geriatr Rehabil. 2003;19(3):206-11

Reason for exclusion: The length of the observational period was not mentioned for the documented falls against each participant. Therefore, there was insufficient data to calculate the outcome of interest.

Smulders E, Enkelaar L, Schoon Y, Geurts AC, van Schrojenstein Lantman-de Valk H, Weerdesteyn V. Falls prevention in persons with intellectual disabilities: Development, implementation, and process evaluation of a tailored multifactorial fall risk assessment and intervention strategy. Res Dev Disabil. 2013;34(9):2788-98.

Reason for exclusion: This study reports on an intervention strategy. The focus was not on the incidence of falls. Outcome of interest was not documented.

Cahill S, Stancliffe RJ, Clemson L, Durvasula S. Reconstructing the fall: individual, behavioural and contexual factors associated with falls in individuals with intellectual disability. J Intellect Dev Disabil. 2014;58(4):321-32.

Reason for exclusion: A qualitative design study reporting on themes that contributed to falls in nine participants. The outcome of interest was not the focus of this study.

Appendix III: Characteristics of Included Studies

\begin{tabular}{|l|l|l|l|l|l|}
\hline Author & Setting & $\begin{array}{l}\text { Methods/Study } \\
\text { design }\end{array}$ & Participants & $\begin{array}{l}\text { Outcome } \\
\text { measures/resul } \\
\text { ts }\end{array}$ & Missing data \\
\hline
\end{tabular}




\begin{tabular}{|c|c|c|c|c|c|}
\hline $\begin{array}{l}\text { Cox et al, } \\
2010^{4} \\
\text { NSW, } \\
\text { Australia }\end{array}$ & $\begin{array}{l}\text { Australian } \\
\text { Medical } \\
\text { Clinic }\end{array}$ & $\begin{array}{l}\text { Retrospective, recall } \\
\text { of falls in past } 12 \\
\text { months from a } \\
\text { question as part of a } \\
\text { survey from a proxy }\end{array}$ & $\begin{array}{l}\text { Sample Size: } \mathrm{n}=114 \\
\text { Age: } \geq 18(18-68) \text { years } \\
\text { Mean age }=38 \\
\text { Gender: } \text { male }=55.3 \% ; \\
\text { female }=44.7 \% \\
\text { Level of ID: } \text { mild }=36.9 \% \text {, } \\
\text { moderate }=41.4 \%, \\
\text { severe/profound }=16.2 \% \text {, } \\
\text { unknown }=5.4 \% \\
\text { Place of residence: formal } \\
\text { care }=52.6 \%, \text { non-formal } \\
\text { care }=47.4 \%\end{array}$ & $\begin{array}{l}\text { Prevalence - } \\
\text { Number of } \\
\text { fallersa; } n=39 \\
(34 \%) \\
\text { Proportion of } \\
\text { participants who } \\
\text { sustained one of } \\
\text { more injuries as } \\
\text { a result of a fall; } \\
\mathrm{n}=31 / 37 \\
(83.8 \%)\end{array}$ & 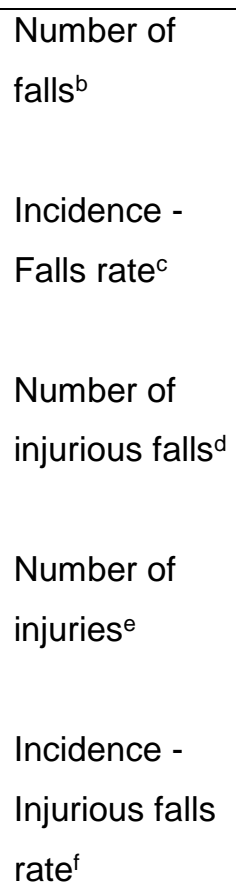 \\
\hline $\begin{array}{l}\text { Finlayson } \\
\text { et al, } \\
2010^{6} \\
\text { Glasgow, } \\
\text { UK }\end{array}$ & $\begin{array}{l}\text { All adults } \\
\text { with ID who } \\
\text { were } \\
\text { registered } \\
\text { with a } \\
\text { GP/family } \\
\text { physician in } \\
\text { the } \\
\text { geographical } \\
\text { area of } \\
\text { Greater } \\
\text { Glasgow, } \\
\text { Scotland }\end{array}$ & $\begin{array}{l}\text { Retrospective recall } \\
\text { of injuries and } \\
\text { accidents over } \\
\text { previous } 12 \text { months } \\
\text { during an interview } \\
\text { using a semi- } \\
\text { structure } \\
\text { questionnaire with a } \\
\text { proxy }\end{array}$ & $\begin{array}{l}\text { Sample size: } \mathrm{n}=511 \\
\text { Age: } \geq 16(16-79) \text { years, } \\
\text { mean }=43.7 \pm 14.2 \\
\text { Gender: } \text { male }=53.4 \% ; \\
\text { female }=46.6 \% \\
\text { Level of ID: mild = } 39.3 \% \text {, } \\
\text { moderate }=22.9 \% \text {, } \\
\text { severe }=19.0 \%, \text { profound } \\
=18.8 \% \\
\text { Place of residence: } \\
\text { Family care }=42.7 \%, \\
\text { Lives independent of any } \\
\text { care }=8.6 \%, \text { Paid care } \\
\text { support }=45.0 \%, \\
\text { Congregate care }=3.7 \%\end{array}$ & 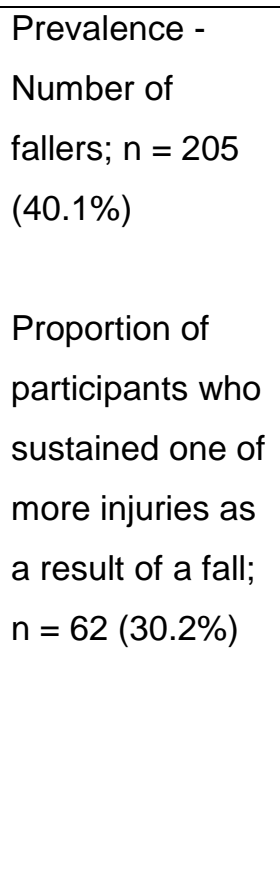 & 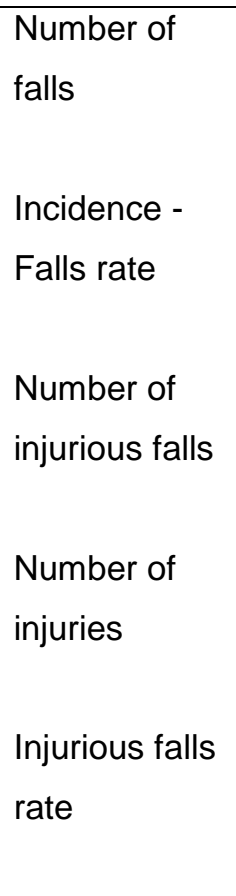 \\
\hline $\begin{array}{l}\text { Grant et } \\
\text { al, } 2001^{15}\end{array}$ & $\begin{array}{l}\text { Adults with } \\
\text { ID living in a } \\
\text { residential or } \\
\text { group home } \\
\text { setting from } \\
\text { an agency } \\
\text { in Canada. }\end{array}$ & $\begin{array}{l}\text { Incident reports were } \\
\text { completed and filed } \\
\text { when a fall occurred } \\
\text { with their clients. } \\
\text { Falls data were } \\
\text { pulled from the } \\
\text { agency's database } \\
\text { where falls incident } \\
\text { reports were kept. } \\
\text { There were } 507\end{array}$ & $\begin{array}{l}\text { Sample size: } \mathrm{n}=114 \\
\text { Age: } 18-77 \text { years, mean }= \\
43.7 \\
\text { Gender: } \text { male }=55.3 \% ; \\
\text { female }=44.7 \% \\
\text { Level of mental } \\
\text { retardation: } \text { mild/moderate } \\
=59.6 \% ; \text { Severe/profound } \\
=40.4 \%\end{array}$ & $\begin{array}{l}\text { Prevalence - } \\
\text { Number of falls } \\
=275 \\
\text { Injurious falls = } \\
79 \% \\
\text { Fallers = } \\
7 \text { out of every } \\
10 \text { people }\end{array}$ & $\begin{array}{l}\begin{array}{l}\text { Number of } \\
\text { fallers }\end{array} \\
\text { Falls rate } \\
\text { Number of } \\
\text { injurious falls } \\
\text { Number of } \\
\text { injuries }\end{array}$ \\
\hline
\end{tabular}




\begin{tabular}{|c|c|c|c|c|c|}
\hline & & $\begin{array}{l}\text { person years of } \\
\text { follow up data. }\end{array}$ & & & $\begin{array}{l}\text { Injurious falls } \\
\text { rate }\end{array}$ \\
\hline $\begin{array}{l}\text { Hsieh et } \\
\text { al, } 2012^{7} \\
\text { United } \\
\text { States of } \\
\text { America } \\
\text { (USA) }\end{array}$ & $\begin{array}{l}\text { Across } 50 \\
\text { states in the } \\
\text { USA }\end{array}$ & $\begin{array}{l}\text { Retrospective recall } \\
\text { of falls in past } 12 \\
\text { months as part of a } \\
\text { Longitudinal Health } \\
\text { and Intellectual } \\
\text { Disability Survey }\end{array}$ & $\begin{array}{l}\text { Sample size: } \mathrm{n}=1515 \\
\text { Age: } \geq 18(18-86) \text { years, } \\
\text { mean }=37.43 \pm 14.48 \\
\text { Gender: } \text { male }=55.1 \% ; \\
\text { female }=44.9 \% \\
\text { Place of residence: Least } \\
\text { supported = } 29.7 \%, \\
\text { Moderately supported = } \\
68.8 \%, \text { Most supported = } \\
3.3 \% \\
\text { Ambulatory status: } \\
\text { Use of walking aid }=8.6 \%\end{array}$ & $\begin{array}{l}\text { Prevalence- } \\
\text { Number of } \\
\text { fallers; } n=372 \\
(24.6 \%)\end{array}$ & 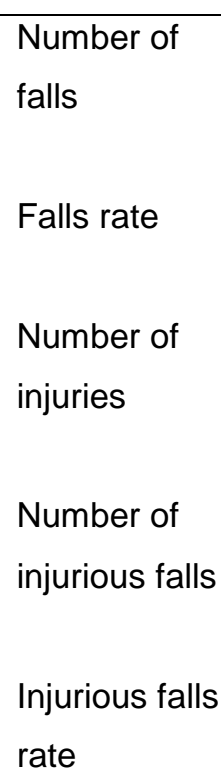 \\
\hline $\begin{array}{l}\text { Pal et al, } \\
2014^{8} \\
\text { New } \\
\text { Zealand } \\
(\mathrm{NZ})\end{array}$ & $\begin{array}{l}3 \text { service } \\
\text { providers; } 2 \\
\text { from South } \\
\text { island, } 1 \text { from } \\
\text { north island } \\
\text { of NZ }\end{array}$ & $\begin{array}{l}\text { Prospective } \\
\text { collection of falls } \\
\text { incidents forms with } \\
\text { monthly follow up } \\
\text { with residential } \\
\text { manager. } \\
3 \text { different cohorts } \\
\text { with a } 3 \text { month and } \\
\text { two, } 6 \text { month } \\
\text { observational period }\end{array}$ & $\begin{array}{l}\text { Sample size: } \mathrm{n}=135 \\
\text { Age: } \geq 18(22-71) \text { years } \\
\text { Gender: } \text { male = 52\%; } \\
\text { female }=65 \% \\
\text { Place of residence: } \\
\text { Residential homes = } 83 \% \text {, } \\
\text { Supported independent } \\
\text { living = } 7 \%, \text { With parents } \\
=8 \%, \text { Unknown = } 2 \% \\
\text { Ambulatory status: } \\
\text { Used assistive devices = } \\
15 \% \\
\text { Independently ambulate = } \\
85 \%\end{array}$ & $\begin{array}{l}\text { Prevalence - } \\
\text { Number of } \\
\text { fallers; } n=37 \\
(27.4 \%) \\
\text { Number of falls } \\
=125\end{array}$ & $\begin{array}{l}\text { Falls rate } \\
\text { Number of } \\
\text { injuries } \\
\text { Number of } \\
\text { injurious falls } \\
\text { Injurious falls } \\
\text { rate }\end{array}$ \\
\hline $\begin{array}{l}\text { Salb et al, } \\
2015^{16}\end{array}$ & $\begin{array}{l}\text { A residential } \\
\text { facility in } \\
\text { Bavaria, } \\
\text { Germany. } \\
>200 \\
\text { residence } \\
\text { with up to } 20 \\
\text { residence } \\
\text { living on the }\end{array}$ & $\begin{array}{l}12 \text { month longitudinal } \\
\text { prospective data } \\
\text { collection of falls } \\
\text { using an electronic } \\
\text { report form } \\
\text { completed by staff } \\
\text { members } \\
\text { Included definition of } \\
\text { fall a }\end{array}$ & $\begin{array}{l}\text { Sample size: } \mathrm{n}=147 \\
\text { Age: } 21 \text { - } 89 \text { years, mean } \\
55.2 \pm 16.1 \\
\text { Gender: } \text { male }=24.5 \% ; \\
\text { female }=75.5 \% \\
\text { Level of ID: } \\
\text { Mild/moderate }=37.4 \% \\
\text { Severe/Profound }=62.6 \% \\
\text { Ambulatory status: } \\
\text { Use of walking aid }=17 \%\end{array}$ & $\begin{array}{l}\text { Prevalence- } \\
\text { Number of } \\
\text { fallers; } n=51 \\
(34.7 \%) \\
\text { Number of falls } \\
=140\end{array}$ & $\begin{array}{l}\text { Number of } \\
\text { injuries } \\
\text { Injurious falls } \\
\text { rate }\end{array}$ \\
\hline
\end{tabular}




\begin{tabular}{|c|c|c|c|c|c|}
\hline & $\begin{array}{l}\text { same } \\
\text { floor/building }\end{array}$ & & & $\begin{array}{l}\text { Number of } \\
\text { injurious falls= } \\
48(34.3 \%) \\
\text { Incidence - } \\
\text { Falls rate = } 0.96 \\
\text { falls per person } \\
\text { year }\end{array}$ & \\
\hline $\begin{array}{l}\text { Smulders } \\
\text { et al, } \\
2013^{14} \\
\text { Netherlan } \\
\text { ds }\end{array}$ & $\begin{array}{l}3 \text { service } \\
\text { providers for } \\
\text { person with } \\
\text { ID in the } \\
\text { Netherlands }\end{array}$ & $\begin{array}{l}\text { Prospective study for } \\
12 \text { months using } \\
\text { monthly fall } \\
\text { registration } \\
\text { calendars. Calendars } \\
\text { were collected end of } \\
\text { the month } \\
\text { Included definition of } \\
\text { fall a }\end{array}$ & $\begin{array}{l}\text { Sample size: } \mathrm{n}=82 \\
\text { Age: }>50 \text { (51.6-84.6) } \\
\text { years, mean = 62.9 } \pm 7.6 \\
\text { Gender: male = 58.5\%; } \\
\text { female }=41.5 \% \\
\text { Place of residence: } \\
\text { Group home = 89\% } \\
\text { Campus facility = 4.9\% } \\
\text { Independent with } \\
\text { ambulatory support = } \\
6.1 \% \\
\text { Inclusion criteria included } \\
\text { able to walk } \\
\text { independently for 10m, } \\
\text { understand simple } \\
\text { instructions, have mild to } \\
\text { moderate ID (IQ 37-70) } \\
\text { Exclusion criteria included } \\
\text { having epilepsy }\end{array}$ & $\begin{array}{l}\text { Prevalence - } \\
\text { Number of } \\
\text { fallers; } n=37 \\
(45 \%) \\
\text { Number of falls } \\
=77 \\
\text { Incidence - } \\
\text { Falls rate = } 1.0 \\
\text { falls per person } \\
\text { year }\end{array}$ & $\begin{array}{l}\begin{array}{l}\text { Number of } \\
\text { injuries }\end{array} \\
\text { Number of } \\
\text { injurious falls } \\
\text { Injurious falls } \\
\text { rate }\end{array}$ \\
\hline $\begin{array}{l}\text { Van } \\
\text { Hanegem } \\
\text { et al, } \\
2014^{35} \\
\text { Netherlan } \\
\text { ds }\end{array}$ & $\begin{array}{l}\text { A residential } \\
\text { facility for } \\
\text { people with } \\
\text { ID }\end{array}$ & $\begin{array}{l}\text { Retrospective data } \\
\text { collection of falls } \\
\text { data at baseline for a } \\
\text { quasi-experimental } \\
\text { study implementing a } \\
\text { falls prevention } \\
\text { exercise program } \\
\text { Included definition of } \\
\text { fallg }\end{array}$ & $\begin{array}{l}\text { Sample size: } \mathrm{n}=39 \\
\text { Age: } \text { mean }=55.1 \pm 10.7 \\
\text { years } \\
\text { Gender: } \text { male }=53.8 \% \text {, } \\
\text { female } 46.2 \% \\
\text { Level of ID: } \\
\text { Mild }=23.1 \% \\
\text { Moderate }=17.9 \% \\
\text { Severe }=53.8 \% \\
\text { Profound }=5.1 \%\end{array}$ & $\begin{array}{l}\text { At baseline - } \\
\text { Number of falls } \\
\text { in last } 12 \\
\text { months = } 131\end{array}$ & 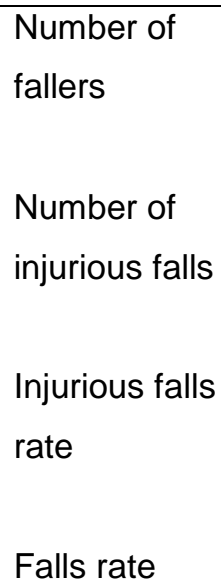 \\
\hline
\end{tabular}




\begin{tabular}{|c|c|c|c|c|c|}
\hline & & & $\begin{array}{l}\text { Inclusion criteria included } \\
\text { high falls risk, recent } \\
\text { history of falls and } \\
\text { ambulant } \\
\text { Exclusion criteria included } \\
\text { not having the ability, } \\
\text { cognitively and } \\
\text { functionally, to participate } \\
\text { in the program and testing }\end{array}$ & & Injurious rate \\
\hline $\begin{array}{l}\text { Wageman } \\
\text { s and } \\
\text { Cluitmans } \\
\text {, 20065 } \\
\text { Netherlan } \\
\text { ds }\end{array}$ & $\begin{array}{l}\text { 338-person } \\
\text { campus- } \\
\text { based } \\
\text { residential } \\
\text { setting in the } \\
\text { Netherlands }\end{array}$ & $\begin{array}{l}33 \text { month } \\
\text { prospective falls data } \\
\text { collection by staff } \\
\text { members. Data } \\
\text { sampled weekly. }\end{array}$ & $\begin{array}{l}\text { Sample size: } \mathrm{n}=338 \\
\text { Age: all age groups }(<20 \text { - } \\
>80) \\
\text { Gender: male }=27.5 \% \text {, } \\
\text { female }=72.5 \% \\
\text { Functional state: } \\
\text { Bedridden }=11 \% \\
\text { Walking outside }=75 \% \\
\text { Walking inside }=4 \% \\
\text { Wheelchair }=10 \%\end{array}$ & $\begin{array}{l}\text { Prevalence - } \\
\text { Number of } \\
\text { fallers; } n=205 \\
(60.6 \%) \\
\text { Number of falls } \\
=1200 \\
\text { Number of } \\
\text { injurious falls = } \\
383\end{array}$ & $\begin{array}{l}\text { Number of } \\
\text { injuries } \\
\text { Falls rate } \\
\text { Injurious falls } \\
\text { rate }\end{array}$ \\
\hline \multicolumn{6}{|c|}{$\begin{array}{l}\text { Footnote: } \\
\text { a Number of fallers = number of participants who sustained more than one fall during the study period } \\
\text { b Number of falls = the total number falls observed during the study period from the total sample population } \\
\text { c Falls rate = Number of falls per person year. Calculated with number of falls/sample size and converted to a } 12 \\
\text { month period. } \\
\text { d Number of injurious falls = Number of falls that resulted in one or more injuries. } \\
\text { e Number of injuries = Number of injuries there are sustained from the falls occurred in the study period } \\
\text { f Injurious falls rate= Number of injuries falls per person year. Calculated with number of injurious falls/ sample size } \\
\text { and converted to a } 12 \text { month period. } \\
\text { g Where not indicated, studies did not indicate that a fall was defined in the study. }\end{array}$} \\
\hline
\end{tabular}

